\title{
Identification of genes encoding hypothetical proteins in open-reading frame expressed sequence tags from mammalian stages of Trypanosoma cruzi
}

\author{
C. Martins ${ }^{1}$, J.L. Reis-Cunha ${ }^{2}$, M.N. Silva ${ }^{1}$, E.G. Pereira ${ }^{1}$, \\ G.J. Pappas Jr., ${ }^{3,4}$ D.C. Bartholomeu ${ }^{2}$ and B. Zingales ${ }^{1}$ \\ ${ }^{1}$ Departamento de Bioquímica, Instituto de Química, \\ Universidade de São Paulo, São Paulo, SP, Brasil \\ ${ }^{2}$ Departamento de Parasitologia, Instituto de Ciências Biológicas, \\ Universidade Federal de Minas Gerais, Belo Horizonte, MG, Brasil \\ ${ }^{3}$ Embrapa Recursos Genéticos e Biotecnologia, Brasília, DF, Brasil \\ ${ }^{4}$ Universidade Católica de Brasília, Brasília, DF, Brasil \\ Corresponding author: B. Zingales \\ E-mail: zingales@iq.usp.br
}

Genet. Mol. Res. 10 (3): 1589-1630 (2011)

Received November 30, 2010

Accepted January 21, 2011

Published August 5, 2011

DOI http://dx.doi.org/10.4238/vol10-3gmr1140

\begin{abstract}
Approximately $50 \%$ of the predicted protein-coding genes of the Trypanosoma cruzi CL Brener strain are annotated as hypothetical or conserved hypothetical proteins. To further characterize these genes, we generated 1161 open-reading frame expressed sequence tags (ORESTES) from the mammalian stages of the VL10 human strain. Sequence clustering resulted in 435 clusters, consisting of 339 singletons and 96 contigs. Significant matches to the T. cruzi predicted gene database were found for $\sim 94 \%$ contigs and $\sim 69 \%$ singletons. These included genes encoding surface proteins, known to be intensely expressed in the parasite mammalian stages and implicated in host cell invasion and/or immune evasion mechanisms. Among 151 contigs and singletons with similarity to predicted hypothetical protein-
\end{abstract}


coding genes and conserved hypothetical protein-coding genes, $83 \%$ showed no match with T. cruzi EST and/or proteome databases. These ORESTES are the first experimental evidence that the corresponding genes are in fact transcribed. Sequences with no significant match were searched against several T. cruzi and National Center for Biotechnology Information non-redundant sequence databases. The ORESTES analysis indicated that 124 predicted conserved hypothetical protein-coding genes and 27 predicted hypothetical protein-coding genes annotated in the CL Brener genome are transcribed in the VL10 mammalian stages. Six ORESTES annotated as hypothetical protein-coding genes showing no match to EST and/or proteome databases were confirmed by Northern blot in VL10. The generation of this set of ORESTES complements the T. cruzi genome annotation and suggests new stageregulated genes encoding hypothetical proteins.

Key words: Trypanosoma cruzi; Mammalian stages; ORESTES; Hypothetical protein-coding genes; Transcription

\section{INTRODUCTION}

Trypanosoma cruzi is the etiological agent of Chagas disease, which afflicts 8 to 10 million people in Latin America. As a consequence of the intense migration of LatinAmericans from endemic regions, Chagas disease has now become a public health concern in several countries, such as the United States, Canada, Spain, and Japan, among others.

T. cruzi is a digenetic protozoan of the order Kinetoplastida, able to infect a great variety of mammalian species and is transmitted by insects of the family Triatominae. Chagas disease has different clinical presentations. Approximately $70 \%$ of seropositive individuals are asymptomatic (indeterminate form), whereas 30\% develop serious cardiac, digestive and/or neurological diseases. Each year, $2-3 \%$ of the asymptomatic individuals will progress to the above-mentioned symptomatic manifestations (Pinto Dias, 2006). The outcome of infection in a particular individual is the result of a set of complex interactions among the genetic make-up of the parasite, the host immunogenetic background and environmental factors (reviewed by Campbell et al., 2004; Macedo et al., 2004).

The biological, biochemical and genetic diversity of $T$. cruzi strains has long been recognized along with their eco-epidemiological complexity, which have been reviewed extensively elsewhere (Macedo and Pena, 1998; Campbell et al., 2004; Miles et al., 2009). Although it has been initially proposed that the major genetic variability of $T$. cruzi results from clonal evolution, increasing evidence indicates that hybridization events must have contributed to the present population structure (Tomazi et al., 2009). Numerous approaches have been used to define the number of relevant $T$. cruzi groups, which have received different designations (reviewed by Zingales et al., 2009). In an effort to unify the nomenclature, there was agreement on an updated system in 2009 and a consensus was reached that $T$. cruzi strains should be referred to by six discrete typing units (DTUs) named T. cruzi I-VI (TcI-VI) (Zingales et al., 2009). A DTU is defined as "sets of stocks that are genetically more related to each other than to any other stock and that are identifiable by common genetic, molecular, or immunological markers" (Tibayrenc, 1998). 
The T. cruzi genome sequencing project was completed in 2005, focusing on the hybrid CL Brener (TcVI) strain (El-Sayed et al., 2005). Assembly parameters were adjusted to contend with the high allelic variation, and partial sequencing of the Esmeraldo cl3 strain from the progenitor TcII DTU allowed the definition of two haplotypes of CL Brener, which were named Esmeraldo and non-Esmeraldo (El-Sayed et al., 2005). An updated version of the CL Brener nuclear genome architecture using the genome project data and synteny information with the Trypanosoma brucei genome has been presented (Weatherly et al., 2009). Over $50 \%$ of the CL Brener genome is represented by repetitive sequences, consisting mostly of large gene families of surface proteins, retrotransposons, subtelomeric repeats (El-Sayed et al., 2005), and the 195-bp satellite DNA (Martins et al., 2008). In the original report, it was concluded that the CL Brener haploid genome contains $\sim 12,000$ proteincoding genes (El-Sayed et al., 2005). However, the number of protein-coding sequences and pseudogenes may be twice the previous estimate (Arner et al., 2007). Putative function could be assigned to $50.8 \%$ of the predicted protein-coding genes on the basis of significant similarity to previously characterized proteins or known functional domains (El-Sayed et al., 2005). This means that for around 6000 proteins the function is unknown and further characterization is needed.

The assessment of $T$. cruzi gene expression was initially obtained by large-scale single pass sequencing of cDNA clones to generate expressed sequence tags (ESTs), mainly of the epimastigote stage encountered in the gut of the triatomid insect vector (reviewed by Aguero et al., 2006). More recently, whole genome oligonucleotide microarrays were employed to determine the extent to which T. cruzi regulates mRNA relative abundances over the course of its complete life-cycle (Minning et al., 2009). In parallel, several proteomic studies have been carried out to validate or discover novel gene products (Atwood III et al., 2005; Ferella et al., 2008).

Most of the genome, transcriptome and proteomic data have been obtained for the CL Brener strain (TcVI), a clone of the CL strain isolated from the vector Triatoma infestans in south Brazil (Zingales et al., 1997). On the other hand, TcII DTU is the primary cause of severe acute and chronic Chagas disease in southeast and central Brazil (Carranza et al., 2009; Miles et al., 2009). Due to the high genetic diversity of T. cruzi strains, transcriptome and proteomic information from human-derived isolates will contribute to the understanding of pathogenic features of this parasite.

Most ESTs (200-500 nt) correspond to the 5' or 3' end of cDNAs, and may therefore be derived from untranslated regions of the transcripts. In contrast, open-reading frame (ORF) EST methodology, called ORESTES (Dias et al., 1997), is an alternative approach that allows the generation of sequences preferentially from the transcript central portion, presumably the most informative region of the gene. The basis of the ORESTES approach is to generate short cDNA templates by reverse transcription (RT) and polymerase chain reaction (PCR) using arbitrarily selected, non-degenerate primers under low-stringency conditions (Dias et al., 1997). Because the position of the amplified fragments within transcripts is highly ordered, a high percentage of fragments encompassing the central portion of the cDNAs is obtained (Dias et al., 1997, 2000). Besides preferential targeting of ORF regions, ORESTES strategy results in a partial equalization of cDNA species, similar to normalization, which in turn facilitates the discovery of low-abundance transcripts (Dias et al., 2000). Such methodology has been successfully used in the definition of the human transcriptome (Dias et al., 2000; Camargo et al., 2001). 
In this study, we undertook a novel T. cruzi transcriptome survey employing the ORESTES approach in order to analyze gene expression in the mammalian stages of the TcII VL10 strain, isolated from a patient in the chronic phase of Chagas disease.

\section{MATERIAL AND METHODS}

\section{T. cruzi VL10 strain and cultivation}

The VL10 strain was isolated from a 15-year-old female patient in Minas Gerais, Brazil. The patient presented a normal electrocardiogram and normal chest X-rays and was considered to be asymptomatic (indeterminate form). The VL10 strain was genotyped as belonging to TcII DTU (Baptista et al., 2006). Trypomastigote and amastigote forms were obtained from the supernatant of monolayers of Simian LLC-MK ${ }_{2}$ cells on the 7th day post-infection, as described previously (Zingales et al., 1997). Epimastigote forms of CL Brener (TcVI DTU) and VL10 strains were cultured in liver infusion-tryptose (LIT) medium with $10 \% \mathrm{FBS}$, at $28^{\circ} \mathrm{C}$.

\section{cDNA template preparation and DNA sequencing}

PolyA $^{+}$RNA was prepared from $10^{9}$ parasites using the $\mu$ MACS kit (Miltenyi Biotec, Auburn, CA, USA) according to manufacturer instructions. RNA samples were treated with DNase I (10 U/50 $\mu \mathrm{g}$ RNA), and the absence of contaminating genomic DNA was confirmed by PCR using primers for the 195-bp satellite DNA and the LSU RNA gene, as previously described (Martins et al., 2008). RNA integrity was confirmed by means of RTPCR using primers for the T. cruzi actin 2 (GenBank accession \#AF494294) and elongation factor 1 (GenBank accession \#L 76077) genes. To produce cDNA templates, the ORESTES methodology (Dias et al., 2000) was employed with some modifications. Samples of 10$30 \mathrm{ng}$ purified DNAse-treated mRNA were heated at $65^{\circ} \mathrm{C}$ for 5 min and then subjected to RT at $37^{\circ} \mathrm{C}$ for $60 \mathrm{~min}$ in the presence of $200 \mathrm{U}$ Superscript II Reverse Transcriptase (Invitrogen) and $15 \mathrm{pmol}$ randomly selected primers in a final volume of $20 \mu \mathrm{L}$. The five primers used for cDNA synthesis and amplification were 18-mers with GC content of 50 to $77 \%$ (PS0229, 5'-GAGTAGACTCTGTCCTGG-3'; PS0236, 5'-TGGGAGTCCATGC GTGCC-3'; PS0225，5'-GTGACCACCAGCTGCTGC-3'; PS0230， 5'-ACCGCAGCG GACAGCGCC-3'; PS0231, 5'-GACAGCAGGACCAAGCCA-3'). After cDNA synthesis, $2 \mu \mathrm{L}$ of each single-stranded cDNA was PCR amplified using the same primer employed in the RT reaction with the Ready-to-go PCR beads system (GE Healthcare) according to manufacturer instructions. Touchdown PCR with 45 cycles was used after cDNA denaturation at $75^{\circ} \mathrm{C}$. Annealing temperatures varied from $52^{\circ}$ to $45^{\circ} \mathrm{C}$ (with progressive reductions of $1^{\circ}$ to $2^{\circ} \mathrm{C}$ per cycle). The samples were run on $1 \%$ low-melting temperature agarose gels and stained with ethidium bromide. After electrophoresis, profiles composed of a DNA smear were size selected from the gels and cloned in pGEM-T Easy vector (Promega) according to standard procedures. Plasmid templates were prepared using 96-Plasmid Purification System kits for the Biomek 2000 Automation Workstation (Beckman). Sequencing was carried out using an ABI 377 automated DNA sequencer (Applied Biosystems Inc.). Nucleotide sequences determined here have been deposited in the GenBank database with the accession numbers GW395924-GW397084. 


\section{EST processing pipeline}

Sequence analysis began with base calling using the phred program (Ewing and Green, 1998). Sequence quality trimming was performed with the lucy program (Chou and Holmes, 2001), and vector masking with the cross match program (Ewing B, unpublished results). The processed sequences were clustered with the CAP3 program (Huang and Madan, 1999), generating the sequence consensi that were used in sequence annotation.

\section{Sequence annotation}

Contigs and singletons were searched as a query against the $T$. cruzi predicted gene database (http://tritrypdb.org/tritrypdb/) using the BLASTN algorithm with low complexity filtering turned off. Matches with a bit score $\geq 100$ were considered to be significant. Sequences with no significant match were searched against the T. cruzi contig database using the same parameters, and those that still did not have a significant match were searched against the $T$. cruzi reads database. Sequences with no significant similarity with any of the three databases were searched against the non-redundant nucleotide and protein sequences at NCBI using BLASTN and BLASTX, respectively. All 435 consensi were also searched against EST/cDNA sequences and proteome T. cru$z i$ databases (http://www.tritrypdb.org) and pfam domains (http://pfam.sanger.ac.uk/) (Supplementary Material S1 - Annotation - ORESTES).

\section{Southern blotting}

Total parasite DNA was obtained as described (Macedo et al., 1992). DNA preparations $(10 \mu \mathrm{g})$ were digested with $P s t$ I restriction enzymes (New England Biolabs), run on $0.8 \%$ agarose gels, and blotted onto nylon membranes (Hybond-N, Amersham Pharmacia) using standard protocols. DNA probes were labeled with $[\alpha-32 \mathrm{P}]$-dATP with the Random Primer DNA Labeling kit (Invitrogen). Probes were hybridized at $60^{\circ} \mathrm{C}$ in $0.1 \%$ Ficoll, $0.05 \%$ PVP, $1 \mathrm{mM}$ EDTA, $3 \mathrm{X} \mathrm{SSC}, 0.1 \% \mathrm{SDS}$ and $100 \mu \mathrm{g} / \mathrm{mL}$ salmon sperm DNA. Blots were washed to a final stringency of $1 \mathrm{X} \mathrm{SSC}, 0.1 \% \mathrm{SDS}$ at $60^{\circ} \mathrm{C}$. The radioactive images were recorded on X-ray films.

\section{RNA blotting}

Total parasite was RNA extracted with the TRIzol reagent according to manufacturer instructions, DNase-treated and separated on formaldehyde-containing 1\% agarose gels in MOPS buffer according to standard procedures and blotted onto nylon membranes (Hybond$\mathrm{N}$, Amersham Pharmacia). DNA probes were labeled as above. Hybridization was carried out in $5 \mathrm{X} \mathrm{SSPE}, 50 \%$ formamide, $5 \mathrm{X}$ Denhardt, $0.5 \% \mathrm{SDS}$ at $42^{\circ} \mathrm{C}$, overnight. Blots were washed to final stringency of $1 \mathrm{X} \mathrm{SSPE}, 0.1 \% \mathrm{SDS}$ at $42^{\circ} \mathrm{C}$, and exposed to X-ray films.

\section{RESULTS AND DISCUSSION}

ORESTES were obtained from DNase-treated PolyA ${ }^{+}$RNA samples of trypomastigote and amastigote forms (3:1 proportion) of the human VL10 strain, recovered in the su- 
pernatant of LLC-MK 2 monolayers. Amastigotes were obtained mostly by the premature lysis of infected cells or from the extracellular differentiation of trypomastigotes. Like trypomastigotes, extracellular amastigotes are capable of invading both professional and non-professional phagocytes and sustain the parasite's life cycle (Fernandes et al., 2006 and cited references).

No amplification of $T$. cruzi abundant genomic sequences, the 195-bp satellite DNA (Martins et al., 2008) and the LSU RNA genes, was observed in the RNA samples, ruling out the presence of contaminating genomic DNA (data not shown). The integrity of the mRNA samples was confirmed by RT-PCR using primers for T. cruzi actin 2 and elongation factor 1 genes (data not shown). Synthesis and amplification of the cDNA templates were obtained with five 18-mer primers. The criterion for primer selection was GC content $\geq 50 \%$, and no specific sequence constraints were imposed (Dias et al., 2000). After cDNA electrophoresis, profiles composed of a DNA smear between 400 and $900 \mathrm{bp}$ were excised from the gels, cloned in pGEM-T Easy vector and sequenced.

In total 1522 ORESTES were generated, of which $68 \%$ were obtained with PS0225 and PS0230 primers. Post-processing to exclude primer and vector sequences, as well as lowquality bases, resulted in 1161 ORESTES with an average phred-generated base-quality value of 20.3 (i.e., $99 \%$ base call accuracy) and average size of $500 \mathrm{nt}$. This size is adequate for transcript identification, since the average size of a $T$. cruzi coding DNA sequence (CDS) is 1513 bp (El-Sayed et al., 2005). We determined that the ORESTES G+C content was 52.7\%, in agreement with the reported CDS G+C content of $53.4 \%$, which is higher than the average $\mathrm{G}+\mathrm{C}$ content of inter-coding regions (47\%) (El-Sayed et al., 2005). Sequence clustering was performed by the CAP3 program, resulting in 479 clusters, which represented $32.4 \%$ of the accepted sequences and indicated a high redundancy level of the library.

Of the 479 clusters, 44 represented contaminant sequences, mainly derived from $\mathrm{Ma}$ cacca mulatta (from the LLC-MK 2 cell monolayers), and were excluded from the analysis. Of the remaining 435 consensi, 96 (22.1\%) contained multiple reads (contigs) and 339 (77.9\%) contained only one ORESTES (singletons) (Table 1). The 435 clusters were searched as query against the following $T$. cruzi databases (http://tritrypdb.org/tritrypdb/): predicted gene contigs, individual reads, EST/cDNA sequences and proteome as described in Material and Methods. Sequences with no significant similarity with $T$. cruzi databases were searched against the non-redundant nucleotide and protein sequences at NCBI using BLASTN and BLASTX, respectively. All 435 consensi were also searched for pfam domains (Supplementary Material S2 - Pfam - ORESTES).

Table 1. ORESTES contig and singleton BLAST matches to nucleotide and protein databases.
\begin{tabular}{lcc}
\hline Description & Number & Percentage \\
\hline ORESTES contigs & 96 & 100.0 \\
Similarity to Trypanosoma cruzi genes & 90 & 93.7 \\
No similarity to coding sequences, but similarity to T. cruzi contigs & 2 & 2.1 \\
No match with any database & 4 & 4.2 \\
ORESTES singletons & 339 & 100.0 \\
Similarity to T. cruzi genes & 234 & 69.0 \\
No similarity to coding sequences, but similarity to T. cruzi contig database & 5 & 1.5 \\
No match with any database & 100 & 29.5 \\
\hline
\end{tabular}


Table 1 summarizes the similarity search results. Around 94\% contigs and 69\% singletons displayed significant matches with $T$. cruzi predicted genes. Considering the reference CL Brener genome haplotypic distribution and classification into Esmeraldo- or non-Esmeraldo-like alleles (El-Sayed et al., 2005), it was possible to identify that $87.5 \%$ contigs and $95.6 \%$ singletons had higher identity with Esmeraldo-like alleles (Supplementary Material S1 - Annotation - ORESTES). This confirms that VL10 and Esmeraldo strains are closely related, both belonging to the TcII DTU (Zingales et al., 2009). A total of 2 contigs and 5 singletons corresponded to non-annotated regions of $T$. cruzi contigs. One of these sequences matched to a maxicircle sequence (mitochondrial genome was not part of the annotated genome dataset) (Westenberger et al., 2006); two sequences were part of missing portions of annotated partial genes, and four sequences were likely untranslated sequences since they were derived from inter-coding regions (Supplementary Material S1 - Annotation - ORESTES). Around $4.2 \%$ contigs and $29.5 \%$ singletons resulted in no matches against either the T. cruzi databases (coding-sequences, contigs or reads) or the non-redundant Genbank protein database. Part of these ORESTES may have been derived from cloning artifacts.

Significant information obtained from highly populated clusters is that the relative levels of gene expression can provide a snapshot of the physiological state of the cells. In this direction, the list of the 15 most populated ORESTES clusters and their best blastn hit against $T$. cruzi genes and contigs is reported in Table 2 . Of these clusters, $40 \%$ represented hypothetical conserved proteins. The putative dispersed gene family 1 (DGF-1) protein was found in two clusters. DGF-1 proteins are encoded by $\sim 500$ genes (El-Sayed et al., 2005) and are localized in the parasite cell membrane. One of the DGF-1 members (DGF1.2) is more abundant in the amastigote stage than in trypomastigotes and epimastigotes, and its expression is developmentally regulated (Lander et al., 2010). Interestingly, transcripts from $D G F-1$ have not been previously reported in $T$. cruzi EST databases (Table 2). This was also the case with the sequences of 13 of the 15 most populated ORESTES clusters (Table 2), indicating that the ORESTES strategy is an alternative methodology to identify novel gene transcripts.

Table 2. Annotation of the most populated ORESTES clusters obtained after selecting the best BLASTN hit against Trypanosoma cruzi databases.

\begin{tabular}{lclll}
\hline $\begin{array}{l}\text { Contig } \\
\text { (No.) }\end{array}$ & $\begin{array}{c}\text { ORESTES } \\
\text { (count) }\end{array}$ & $\begin{array}{l}\text { Best BLASTN hit against } \\
\text { T. cruzi genes and contigs }\end{array}$ & Annotation & $\begin{array}{l}\text { Best BLASTN hit } \\
\text { against } T \text {. cruzi ESTs }\end{array}$ \\
\hline 16 & 6 & Tc00.1047053508179.70 & GPR1/FUN34/yaaH family, putative & Null \\
11 & 8 & Tc00.1047053507653.40 & Dispersed gene family protein 1 (DGF-1), putative & Null \\
90 & 8 & Tc00.1047053509865.9 & Retrotransposon hot spot (RHS) protein, putative & Null \\
89 & 8 & Tc00.1047053507479.29 & NUP-1 protein (pseudogene), putative & Null \\
20 & 9 & Tc00.1047053510431.190 & Hypothetical protein, conserved & Null \\
64 & 10 & Tc00.1047053507083.109 & Hypothetical protein, conserved & Null \\
62 & 12 & Tc00.1047053509157.170 & Trans-sialidase, putative & Null \\
54 & 14 & Tc00.1047053507099.80 & ABC transporter, putative & Null \\
95 & 14 & Tc00.1047053506481.30 & Hypothetical protein, conserved & Null \\
35 & 15 & Tc00.1047053399389.10 & Hypothetical protein, conserved & Null \\
6 & 22 & Tc00.1047053511727.290 & RNA binding protein, putative & TENU4719 epimastigote normalized \\
cDNA library (5' mRNA sequence) \\
& & & & TENU1365 epimastigote normalized \\
cDNA library (3' mRNA sequence)
\end{tabular}


Analysis of the best BLASTX hits against $T$. cruzi proteome databases indicated that of these 15 ORESTES clusters, only the proteins related to contig89 (putative NUP-1 protein, pseudogene) and contig90 (putative retrotransposon hot spot (RHS) protein) have been deposited in this database (Supplementary Material S1 - Annotation - ORESTES). Coincidentally, RHS protein was characterized in amastigote, trypomastigote and metacyclic infective stages, and the nuclear envelope protein NUP-1, in the metacyclic insect stage. For the highly populated contig42, no match was found with any database (Table 2).

Next we analyzed the ORESTES matching T. cruzi predicted genes (Figure 1). The majority of the contigs $(55 \%)$ and large proportion of singletons $(43 \%)$ were derived from known coding sequences previously reported in $T$. cruzi and/or other organisms, and annotated here as predicted protein-coding genes. These included genes encoding surface proteins such as the trans-sialidase/gp85 superfamily, mucin-associated surface protein (MASP), mucin TcMUCII, DGF-1, and surface protease GP63 (Supplementary Material S1 - Annotation - ORESTES), all known to be intensely expressed in the mammalian stages of the parasite (Frasch, 2000; Grandgenett et al., 2000; Buscaglia et al., 2004; Bartholomeu et al., 2009; Lander et al., 2010).
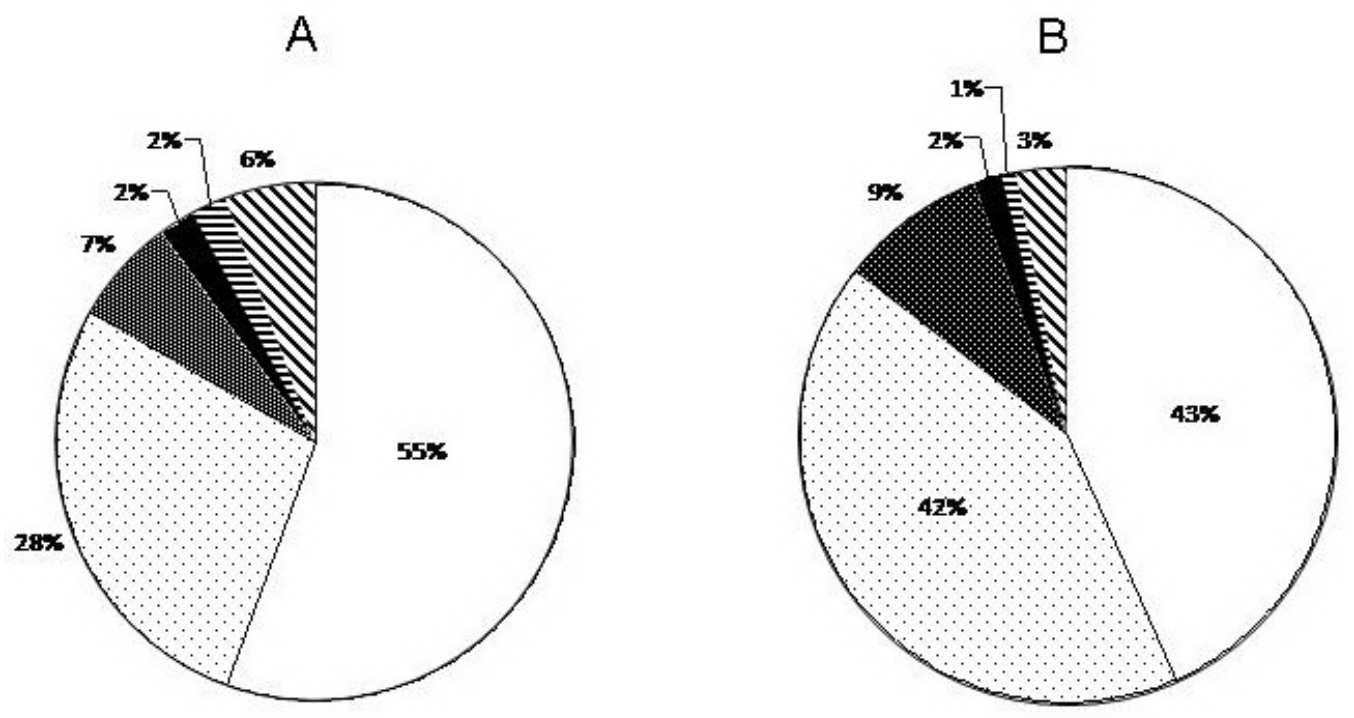

Predicted protein-coding genes

Predicted conserved hypothetical protein-coding genes

Predicted hypothetical protein-coding genes

Retrotransposons

目 195-bp sated lite DNA

ब Ribosomal RNA

Figure 1. Distribution of the ORESTES contigs ( $N=90$; Panel A) and singletons $(\mathrm{N}=234$; Panel $\mathrm{B})$ among classes of Trypanosoma cruzi predicted genes. 
In comparison with Leishmania major and T. brucei genomes, T. cruzi shows a remarkable expansion of these gene families, corresponding to approximately $20 \%$ of the total protein-coding genes. Some of these families are T. cruzi-specific such as MASP, mucin TcMUC and DGF-1, while others are much more expanded in T. cruzi compared with T. bruce $i$ and/or L. major, such as gp85/trans-sialidase and GP63 (El-Sayed et al., 2005 and cited references). Each of the three parasite species evolved a specific surface coat adapted for survival and proliferation in the different niches they occupy in the mammalian host. Unlike T. brucei, which is exclusively extracellular, and L. major, which infects macrophages, $T$. cruzi has the ability to infect and proliferate within a large variety of host cell types. It has been demonstrated that several of these T. cruzi surface proteins are glycosylated and mediate host cell attachment and invasion and/or intracellular replication (AcostaSerrano et al., 2001; Kulkarni et al., 2009; Albertti et al., 2010). Additionally, some of these molecules are implicated in immune evasion mechanisms (Pereira-Chioccola et al., 2000; Pitcovsky et al., 2002; Gao et al., 2002).

We have also found that a small proportion of the contigs and singletons match retroelements, related to the modeling of T. cruzi genome (El-Sayed et al., 2005), the transcribed repetitive 195-bp satellite DNA sequence (Martins et al., 2008) and ribosomal RNA genes.

In addition to $T$. cruzi genes experimentally characterized, we also identified a considerable number of contigs (28\%) and a large proportion of singletons $(42 \%)$ corresponding to genes matching hypothetical proteins also identified in other organisms, but with unknown function (annotated as predicted conserved hypothetical protein-coding genes) (Figure 1). Of particular interest are a number of contigs (7\%) and singletons $(9 \%)$ matching hypothetical proteins, which are putatively $T$. cruzi-specific genes.

Aiming to investigate the genomic organization of some ORESTES sequences, Southern blots of total DNA of epimastigote forms of CL Brener and VL10 strains were digested with PstI and hybridized with five probes: three ORESTES that showed no match with any database (one member of contig42, contig59 and the singleton TCA236-IQ001_ E12_B_10.ab1); one member of contig83 (DGF-1; GenBank accession \#GW396523) and contig23 (hypothetical protein, conserved; GenBank accession \#GW396011) (Figure 2). No hybridization signal was obtained for the highly populated contig42 probe (Table 2), confirming that these sequences are artifacts. On the other hand, the probes of the two other no-match ORESTES (contig59 and singleton TCA236-IQ001_E12_.B_10.ab1) identified DNA bands in the two strains (Figure 2B and C). Some differences in the organization of $D G F-1$ in the genome of CL Brener and VL10 could be detected (Figure 2D). In contrast, the same hybridization pattern in the two strains was observed for the conserved hypothetical protein-coding gene of contig23 (Figure 2E).

Among the ORESTES contigs and singletons with similarity to predicted conserved hypothetical protein-coding genes and predicted hypothetical protein-coding genes (total 151), $82.8 \%$ (125/151) showed no matches against T. cruzi EST and proteome databases (Supplementary Material S1 - Annotation - ORESTES). These ORESTES sequences are the first experimental evidence that the corresponding genes are in fact transcribed. Those matching hypothetical protein-coding genes, which showed no similarity to EST and proteome data (12 in total), deserve further investigation since they are likely to be T. cruzi-specific and expressed in the mammalian infective stages. 


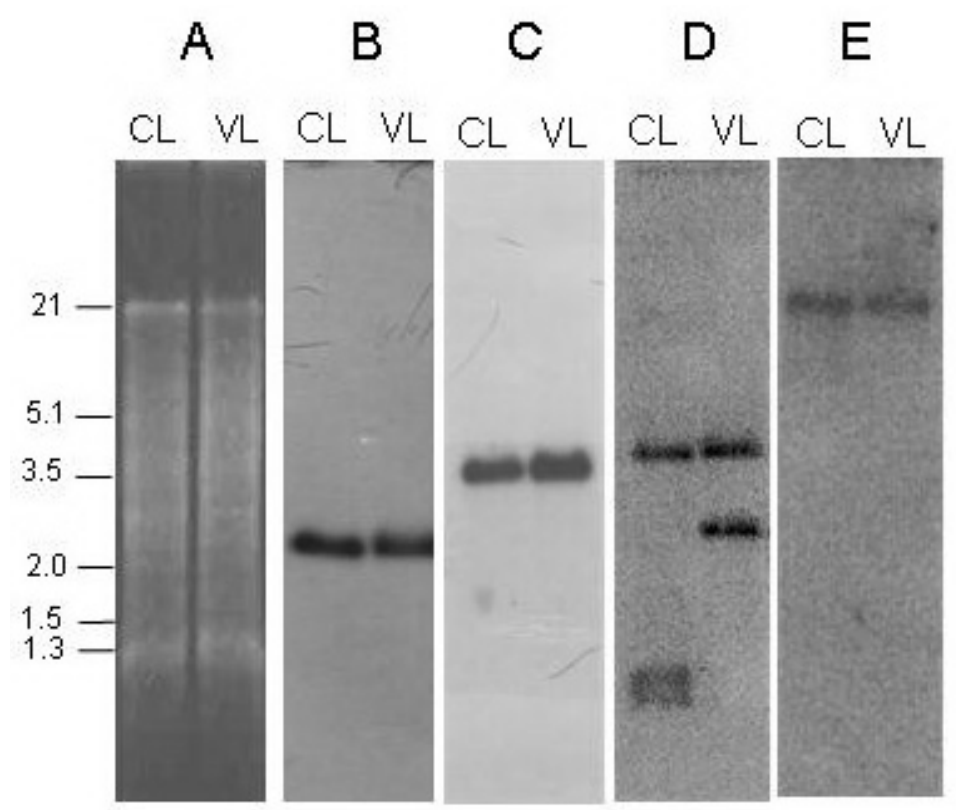

Figure 2. Genomic organization of ORESTES. Southern blot of total DNA of CL Brener (CL) and VL10 (VL) strains digested with PstI. A. Ethidium bromide-stained gel and hybridizations with ${ }^{32} \mathrm{P}-$ labeled probes; B. contig59 (no match); C. singleton (TCA236-IQ001_E12_.B_10.ab1, no match); D. contig83 (GenBank accession

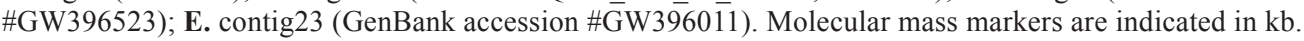

To further characterize the 151 contigs and singletons matching hypothetical and conserved hypothetical proteins, the corresponding proteins were searched for conserved domains against the Pfam database (http://pfam.sanger.ac.uk/), with a cutoff e-value of $10^{-5}$ (Supplementary Material S2 - Pfam - ORESTES). The data are summarized in Table 3. Considering the 31 ORESTES contigs, Pfam domains were identified in 7 of 25 conserved hypothetical proteins and in 1 of 6 hypothetical proteins. Regarding the 120 singletons, Pfam domains were identified in 19 of 99 conserved hypothetical proteins and in 2 of 21 hypothetical proteins (Table 3). Additionally, conserved protein domains could be recognized in 1 of the 6 contigs and 2 of the 14 singletons annotated as hypothetical protein-coding genes and which showed no match against EST and proteome databases (Table 3).

Table 3. Pfam domains of conserved hypothetical proteins and hypothetical proteins of ORESTES contigs and singletons.

\begin{tabular}{|c|c|c|c|c|}
\hline \multirow[t]{2}{*}{ Description } & \multicolumn{2}{|c|}{ Total } & \multicolumn{2}{|c|}{ No match with EST and proteome databases } \\
\hline & Number & Pfam domains & Number & Pfam domains \\
\hline \multicolumn{5}{|l|}{ Contigs } \\
\hline Conserved hypothetical proteins & 25 & 7 & 22 & 7 \\
\hline Hypothetical proteins & 6 & 1 & 6 & 1 \\
\hline \multicolumn{5}{|l|}{ Singletons } \\
\hline Conserved hypothetical proteins & 99 & 19 & 83 & 18 \\
\hline Hypothetical proteins & 21 & 2 & 14 & 2 \\
\hline
\end{tabular}


In our analysis, we found several ORESTES annotated as hypothetical proteincoding genes that showed no match against EST and proteome databases. Since, in principle, these genes could be T. cruzi-specific, we decided to confirm the transcript abundance of some of these genes by means of Northern blot assays with DNase-treated total RNA of trypomastigote + amastigote forms of the VL10 strain. Because most of T. cruzi ESTs were obtained from CL Brener epimastigotes (reviewed by Aguero et al., 2006), RNA blots of this parasite stage were also included in the analysis (Figure 3). The blots were hybridized with six labeled ORESTES probes. Two probes corresponded to one member of contig03 (GenBank accession \#GW395938) and one member of contig25 (GenBank accession \#GW396121), and the other four probes to singletons (GenBank accession \#GW396611, \#GW396648, \#GW396850, and \#GW396862) (Figure 3). Transcripts could be detected in the mammalian forms of VL10 for all six probes, corroborating the ORESTES data indicating that these genes are transcribed. Only the probe derived from contig25 also identified transcripts in CL Brener epimastigotes (Figure 3, panel $\mathrm{H}$ ). At least three strong hybridization bands were detected by one singleton probe (GenBank accession \#GW396862) (Figure 3, panel G). We verified that the hypothetical protein-coding gene, which was the best hit for this singleton matched six other hypothetical protein-coding genes (e-value ranging from $10^{-32}$ to $10^{-146}$ ) with coding regions varying in length from 585 to $1140 \mathrm{bp}$. Some of these genes were located at contig ends, and therefore, the size of their corresponding transcripts could not be estimated based on the genome data. Therefore, the various hybridization bands could be originated by cross-hybridization of the probe with these related sequences. For all the other probes, the transcript sizes were compatible with the length of the CDS plus flanking sequences, most probably untranslated regions.

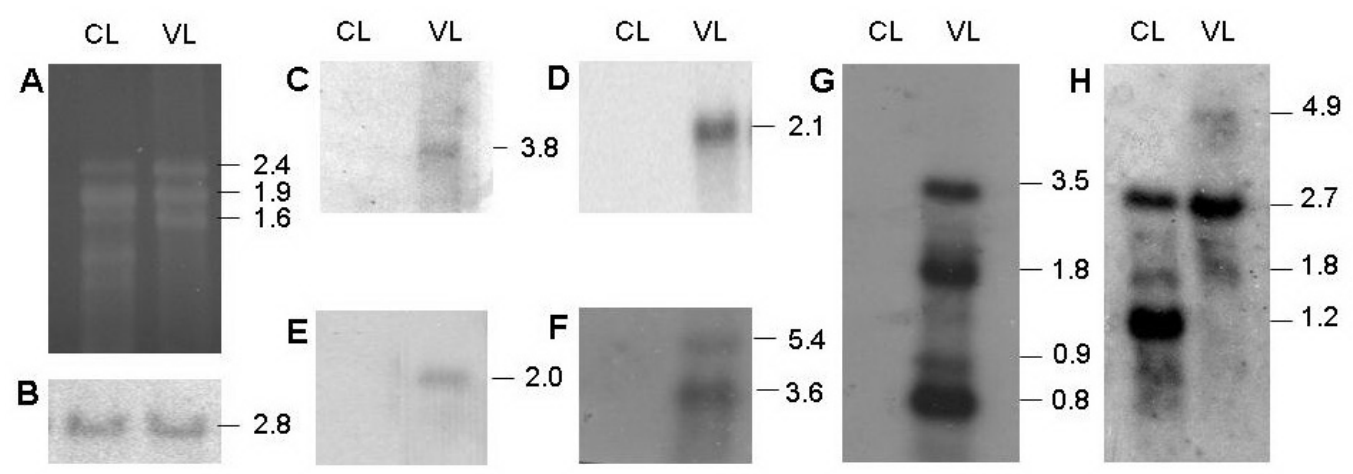

Figure 3. Transcription of hypothetical protein-coding genes. Blots of DNase-treated total RNA of CL Brener epimastigotes (CL) and VL10 trypomastigote + amastigote forms (VL). A. Ethidium bromide-stained agarose gel. The blots were hybridized with ${ }^{32} \mathrm{P}$-labeled probes; B. Actin 2 housekeeping gene; $\mathbf{C}$. singleton (GenBank accession \#GW396611); D. singleton (GenBank accession \#GW396648); E. singleton (GenBank accession \#GW396850); F. contig03 (GenBank accession \#GW395938); G. singleton (GenBank accession \#GW396862); H. contig25 (GenBank accession \#GW396121). The estimated sizes (in $\mathrm{kb}$ ) of the transcripts are indicated on the right side of the panels. 
The data presented in Figure 3 indicating that five ORESTES probes of hypothetical protein-coding genes recognized RNA transcripts only in the VL10 mammalian stages strongly suggest that the level of expression of these genes is developmentally regulated. In fact, differential mRNA levels conferring stage-regulated gene expression have been detected on T. cruzi microarrays (Minning et al., 2009) and in several other studies (reviewed by Teixeira and Da Rocha, 2003). On the other hand, the differential hybridization between the CL Brener (TcVI) and VL10 (TcII) strains could be related to genetic differences between the two T. cruzi DTUs (Miles et al., 2009; Zingales et al., 2009).

In conclusion, the ORESTES analysis led to the verification that 124 predicted conserved hypothetical protein-coding genes and 27 predicted hypothetical protein-coding genes annotated in the CL Brener genome are transcribed in the mammalian stages of the VL10 strain. The generation of this small set of ORESTES helps to complement the T. cruzi genome annotation, since the detection of missing portions of genes belonging to the contigs derived from the non-annotated dataset has been possible. The verification that some genes annotated as coding for hypothetical proteins are in fact transcribed will stimulate the characterization of the corresponding proteins that could not be identified by the current proteomic methods due to their low levels or physical properties. This can contribute to a better understanding of the parasite biology and pathogenicity since these are a priori $T$. cruzi-specific genes. At the same time, this approach provides information on the putative developmental expression of the genes, helping in the use of more assertive strategies for functional studies.

\section{ACKNOWLEDGMENTS}

We are greatly indebted to Dr. Emmanuel Dias Neto and Dr. Elida Ojopi for insightful suggestions. Research supported by Fundação de Amparo à Pesquisa do Estado de São Paulo (FAPESP) and Ministério de Ciência e Tecnologia/Conselho Nacional de Desenvolvimento Científico e Tecnológico/Ministério da Saúde (MCT/CNPq/MS-SCTIE-DECIT - Edital de Doenças Negligenciadas) to B. Zingales, UNICEF/UNDP/World Bank WHO for Research and Training in Tropical Diseases, Fundação de Amparo à Pesquisa do Estado de Minas Gerais (FAPEMIG), and Conselho Nacional de Desenvolvimento Científico e Tecnológico (CNPq) to D.C. Bartholomeu. All authors, except M.N. Silva are recipients of CNPq fellowships.

\section{REFERENCES}

Acosta-Serrano A, Almeida IC, Freitas-Junior LH, Yoshida N, et al. (2001). The mucin-like glycoprotein super-family of Trypanosoma cruzi: structure and biological roles. Mol. Biochem. Parasitol. 114: 143-150.

Aguero F, Zheng W, Weatherly DB, Mendes P, et al. (2006). TcruziDB: an integrated, post-genomics community resource for Trypanosoma cruzi. Nucleic Acids Res. 34: D428-D431.

Albertti LA, Macedo AM, Chiari E, Andrews NW, et al. (2010). Role of host lysosomal associated membrane protein (LAMP) in Trypanosoma cruzi invasion and intracellular development. Microb. Infect. 12: 784-789.

Arner E, Kindlund E, Nilsson D, Farzana F, et al. (2007). Database of Trypanosoma cruzi repeated genes: 20,000 additional gene variants. BMC Genom. 8: 391.

Atwood JA III, Weatherly DB, Minning TA, Bundy B, et al. (2005). The Trypanosoma cruzi proteome. Science 309: 473-476.

Baptista CS, Vencio RZ, Abdala S, Carranza JC, et al. (2006). Differential transcription profiles in Trypanosoma cruzi associated with clinical forms of Chagas disease: Maxicircle NADH dehydrogenase subunit 7 gene truncation in asymptomatic patient isolates. Mol. Biochem. Parasitol. 150: 236-248.

Bartholomeu DC, Cerqueira GC, Leao AC, daRocha WD, et al. (2009). Genomic organization and expression profile of 
the mucin-associated surface protein (masp) family of the human pathogen Trypanosoma cruzi. Nucleic Acids Res. 37: 3407-3417.

Buscaglia CA, Campo VA, Di Noia JM, Torrecilhas AC, et al. (2004). The surface coat of the mammal-dwelling infective trypomastigote stage of Trypanosoma cruzi is formed by highly diverse immunogenic mucins. J. Biol. Chem. 279: 15860-15869.

Camargo AA, Samaia HP, Dias-Neto E, Simao DF, et al. (2001). The contribution of 700,000 ORF sequence tags to the definition of the human transcriptome. Proc. Natl. Acad. Sci. U. S. A. 98: 12103-12108.

Campbell DA, Westenberger SJ and Sturm NR (2004). The determinants of Chagas disease: connecting parasite and host genetics. Curr. Mol. Med. 4: 549-562.

Carranza JC, Valadares HM, D'Avila DA, Baptista RP, et al. (2009). Trypanosoma cruzi maxicircle heterogeneity in Chagas disease patients from Brazil. Int. J. Parasitol. 39: 963-973.

Chou HH and Holmes MH (2001). DNA sequence quality trimming and vector removal. Bioinformatics. 17: 1093-1104.

Dias NE, Caballero OL, Vidigal TH, Pena SD, et al. (1997). Partially degraded DNA of parasitological interest serves as an adequate template for the production of random amplified polymorphic DNAs (RAPDs). J. Parasitol. 83: 753-755.

Dias NE, Correa RG, Verjovski-Almeida S, Briones MR, et al. (2000). Shotgun sequencing of the human transcriptome with ORF expressed sequence tags. Proc. Natl. Acad. Sci. U. S. A. 97: 3491-3496.

El-Sayed NM, Myler PJ, Bartholomeu DC, Nilsson D, et al. (2005). The genome sequence of Trypanosoma cruzi, etiologic agent of Chagas disease. Science 309: 409-415.

Ewing B and Green P (1998). Base-calling of automated sequencer traces using phred. II. Error probabilities. Genome Res. 8: 186-194.

Ferella M, Nilsson D, Darban H, Rodrigues C, et al. (2008). Proteomics in Trypanosoma cruzi - localization of novel proteins to various organelles. Proteomics 8: 2735-2749.

Fernandes AB, Neira I, Ferreira AT and Mortara RA (2006). Cell invasion by Trypanosoma cruzi amastigotes of distinct infectivities: studies on signaling pathways. Parasitol. Res. 100: 59-68.

Frasch AC (2000). Functional diversity in the trans-sialidase and mucin families in Trypanosoma cruzi. Parasitol. Today 16: 282-286.

Gao W, Wortis HH and Pereira MA (2002). The Trypanosoma cruzi trans-sialidase is a T cell-independent B cell mitogen and an inducer of non-specific Ig secretion. Int. Immunol. 14: 299-308.

Grandgenett PM, Coughlin BC, Kirchhoff LV and Donelson JE (2000). Differential expression of GP63 genes in Trypanosoma cruzi. Mol. Biochem. Parasitol. 110: 409-415.

Huang X and Madan A (1999). CAP3: A DNA sequence assembly program. Genome Res. 9: 868-877.

Kulkarni MM, Olson CL, Engman DM and McGwire BS (2009). Trypanosoma cruzi GP63 proteins undergo stage-specific differential posttranslational modification and are important for host cell infection. Infect. Immun. 77: 2193-2200.

Lander N, Bernal C, Diez N, Anez N, et al. (2010). Localization and developmental regulation of a dispersed gene family 1 protein in Trypanosoma cruzi. Infect. Immun. 78: 231-240.

Macedo AM and Pena SD (1998). Genetic variability of Trypanosoma cruzi: Implications for the pathogenesis of Chagas disease. Parasitol. Today 14: 119-124.

Macedo AM, Martins MS, Chiari E and Pena SD (1992). DNA fingerprinting of Trypanosoma cruzi: a new tool for characterization of strains and clones. Mol. Biochem. Parasitol. 55: 147-153.

Macedo AM, Machado CR, Oliveira RP and Pena SD (2004). Trypanosoma cruzi: genetic structure of populations and relevance of genetic variability to the pathogenesis of Chagas disease. Mem. Inst. Oswaldo Cruz 99: 1-12.

Martins C, Baptista CS, Ienne S, Cerqueira GC, et al. (2008). Genomic organization and transcription analysis of the 195bp satellite DNA in Trypanosoma cruzi. Mol. Biochem. Parasitol. 160: 60-64.

Miles MA, Llewellyn MS, Lewis MD, Yeo M, et al. (2009). The molecular epidemiology and phylogeography of Trypanosoma cruzi and parallel research on Leishmania: looking back and to the future. Parasitology 136: 15091528.

Minning TA, Weatherly DB, Atwood J, III, Orlando R, et al. (2009). The steady-state transcriptome of the four major lifecycle stages of Trypanosoma cruzi. BMC Genom. 10: 370.

Pereira-Chioccola VL, Acosta-Serrano A, Correia dA, I, Ferguson MA, et al. (2000). Mucin-like molecules form a negatively charged coat that protects Trypanosoma cruzi trypomastigotes from killing by human anti-alpha-galactosyl antibodies. J. Cell Sci. 113 (Pt 7): 1299-1307.

Pinto Dias JC (2006). The treatment of Chagas disease (South American trypanosomiasis). Ann. Intern. Med. 144: 772-774.

Pitcovsky TA, Buscaglia CA, Mucci J and Campetella O (2002). A functional network of intramolecular cross-reacting epitopes delays the elicitation of neutralizing antibodies to Trypanosoma cruzi trans-sialidase. J. Infect. Dis. 186: 397-404. 
Teixeira SMR and Da Rocha WD (2003). Control of gene expression and genetic manipulation in Trypanosomatidae. Genet. Mol. Res. 2: 148-158.

Tibayrenc M (1998). Genetic epidemiology of parasitic protozoa and other infectious agents: the need for an integrated approach. Int. J. Parasitol. 28: 85-104.

Tomazi L, Kawashita SY, Pereira PM, Zingales B, et al. (2009). Haplotype distribution of five nuclear genes based on network genealogies and Bayesian inference indicates that Trypanosoma cruzi hybrid strains are polyphyletic. Genet. Mol. Res. 8: 458-476.

Weatherly DB, Boehlke C and Tarleton RL (2009). Chromosome level assembly of the hybrid Trypanosoma cruzi genome. BMC Genom. 10: 255.

Westenberger SJ, Cerqueira GC, El-Sayed NM, Zingales B, et al. (2006). Trypanosoma cruzi mitochondrial maxicircles display species- and strain-specific variation and a conserved element in the non-coding region. BMC Genom. 7: 60 .

Zingales B, Pereira ME, Almeida KA, Umezawa ES, et al. (1997). Biological parameters and molecular markers of clone CL Brener - the reference organism of the Trypanosoma cruzi genome project. Mem. Inst. Oswaldo Cruz 92: 811814.

Zingales B, Andrade SG, Briones MR, Campbell DA, et al. (2009). A new consensus for Trypanosoma cruzi intraspecific nomenclature: second revision meeting recommends TcI to TcVI. Mem. Inst. Oswaldo Cruz 104: 1051-1054. 
Transcriptome of Trypanosoma cruzi mammalian stages

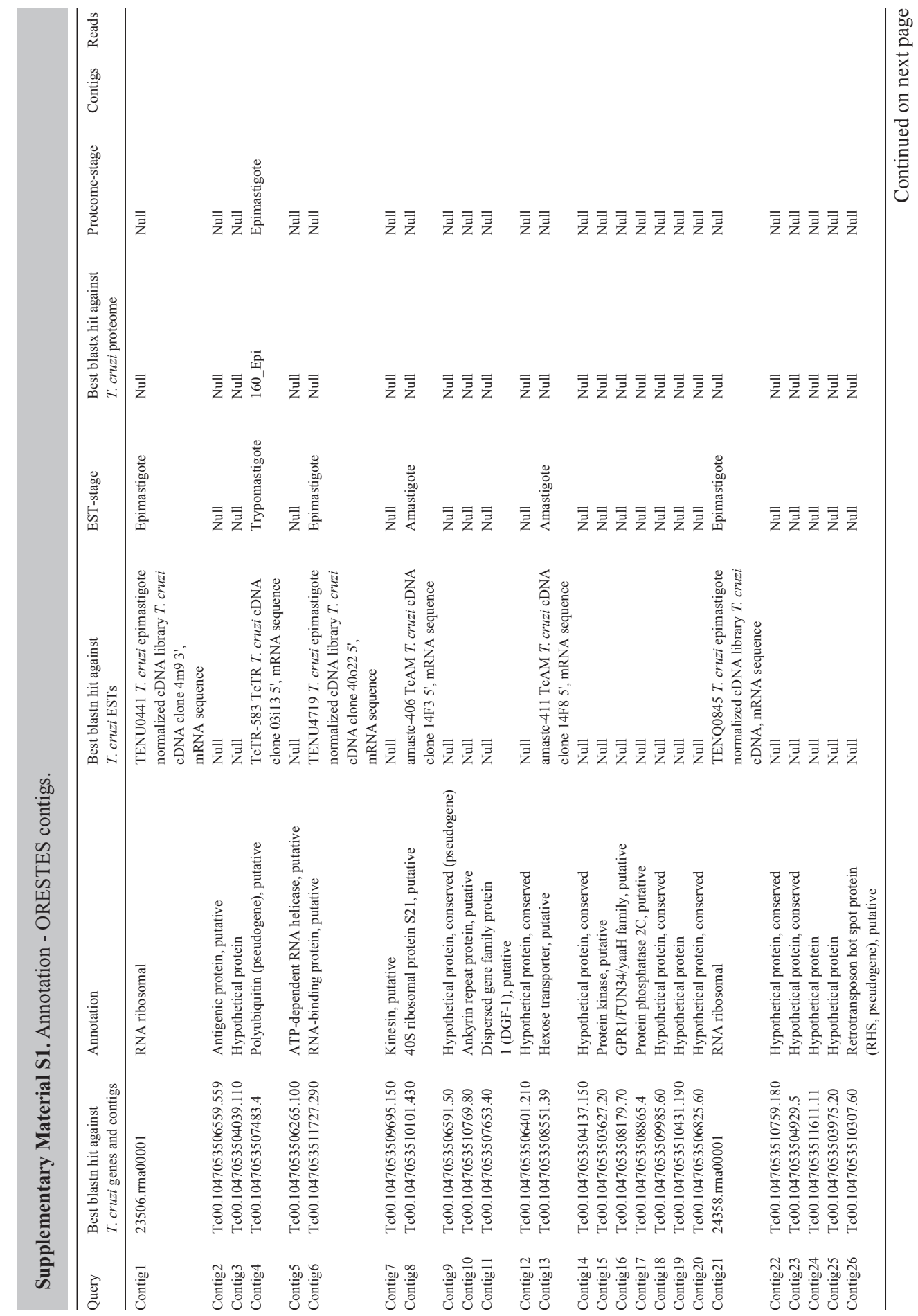


C. Martins et al.

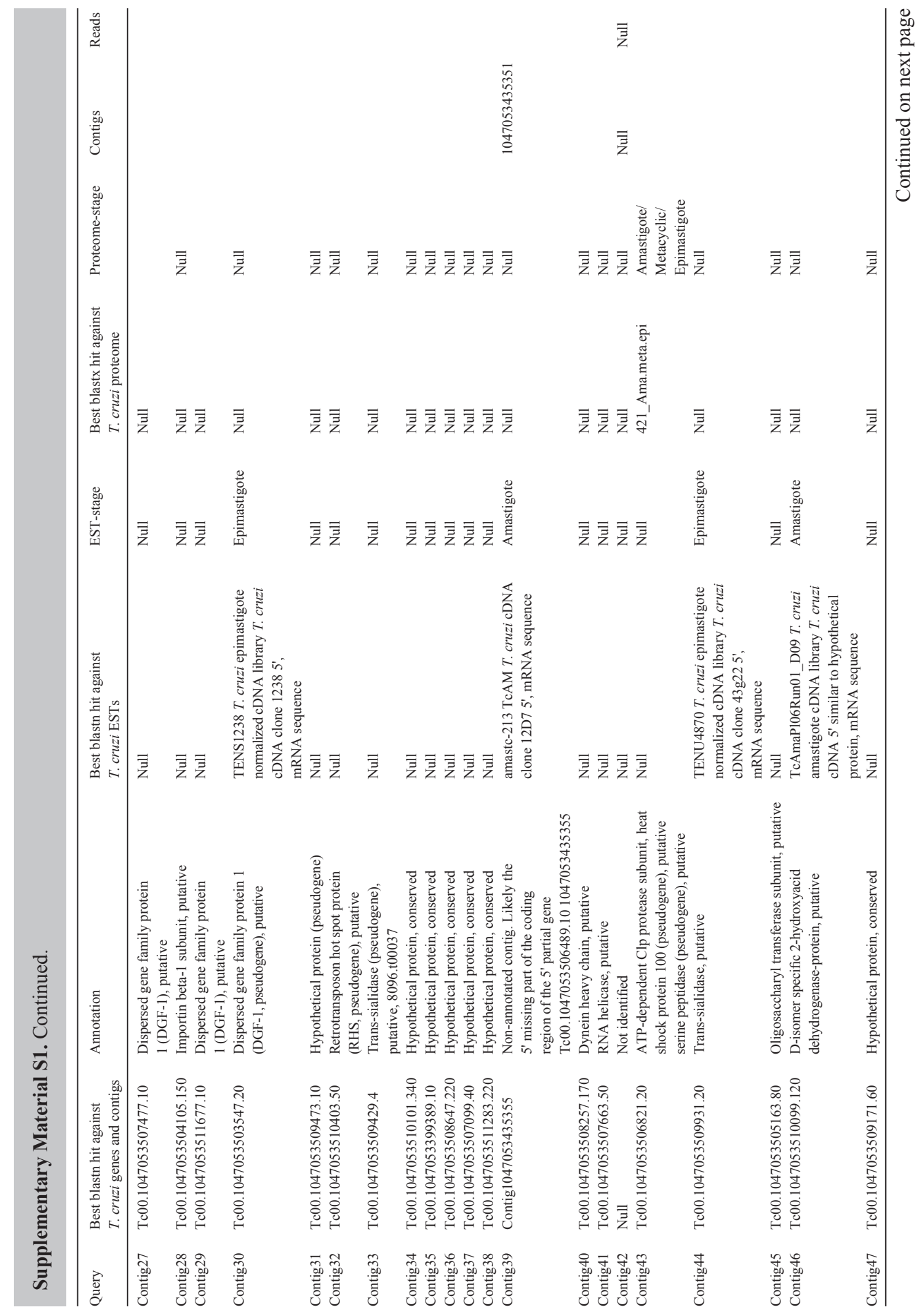


Transcriptome of Trypanosoma cruzi mammalian stages

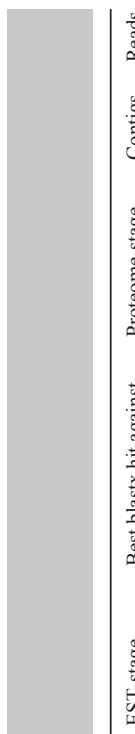

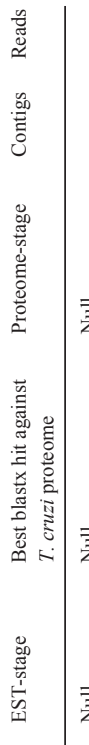

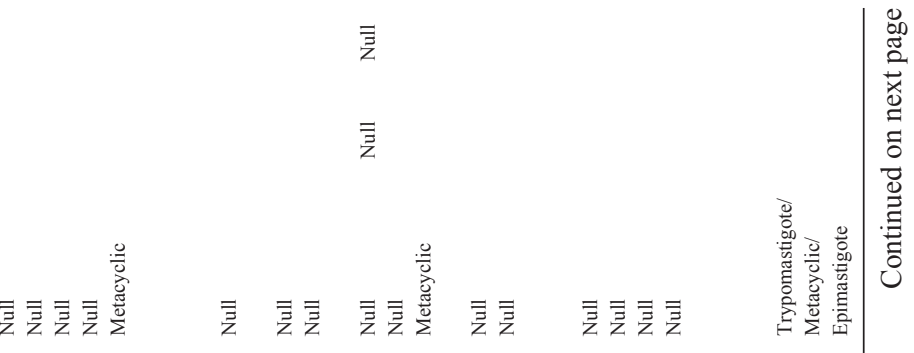

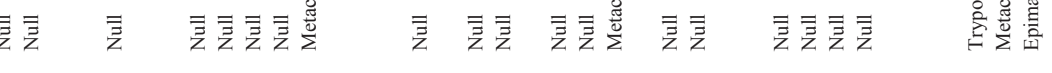

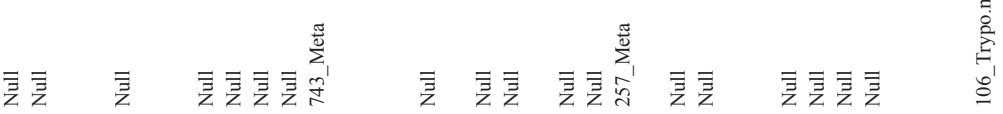

言

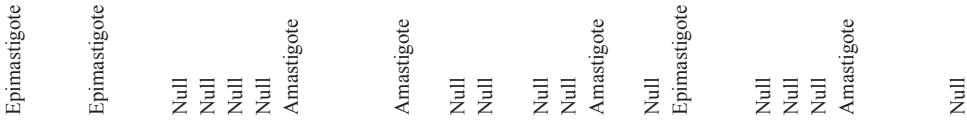

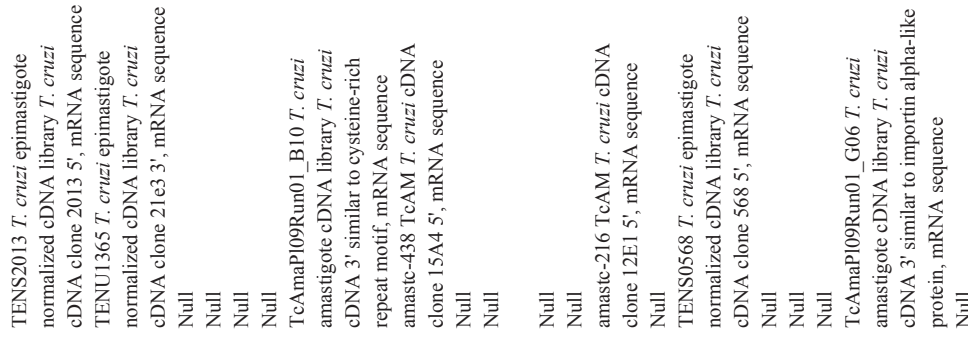

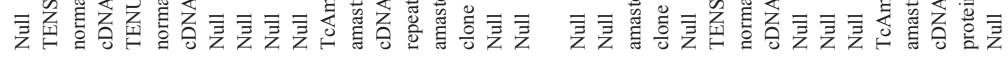

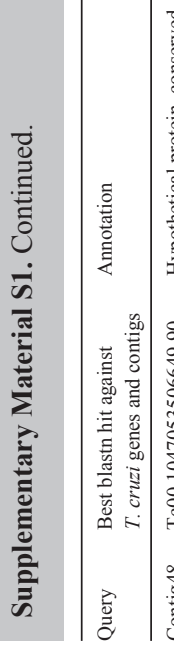

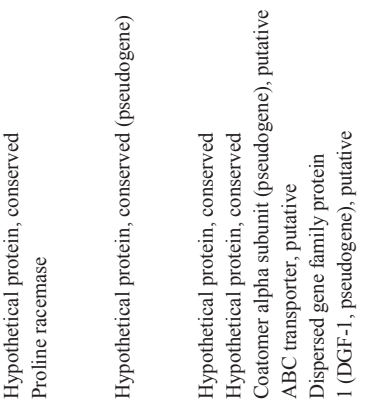

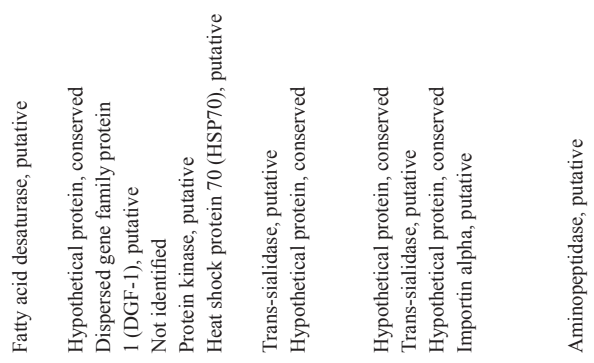

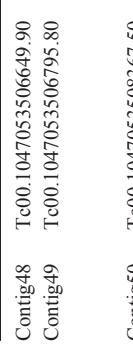

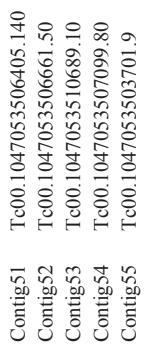

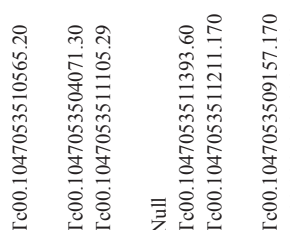

은 둥의 을

ले ले

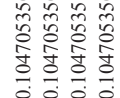

造迢通

Hin min 
C. Martins et al.

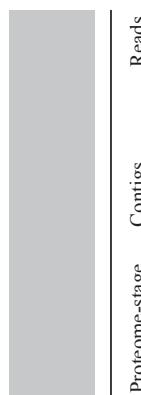

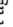

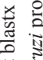

焉

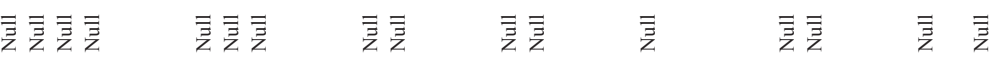

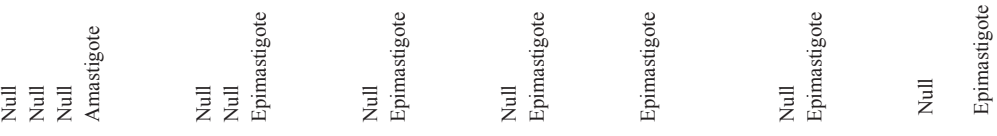

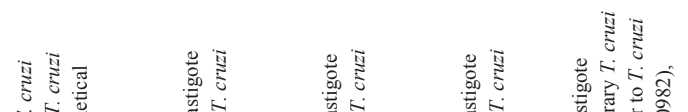

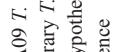

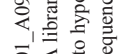

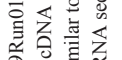

을

$\overline{\overline{\mathrm{z}}}$

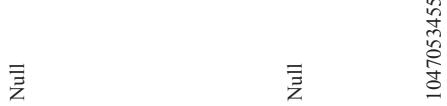

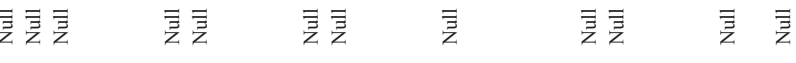

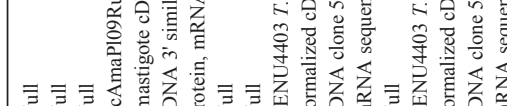

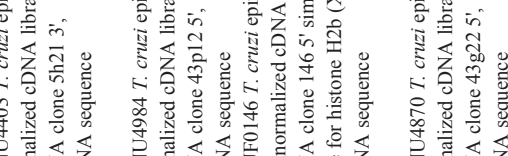

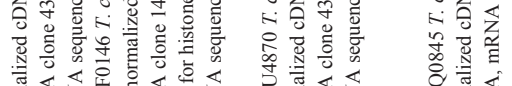

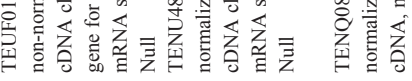

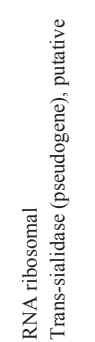

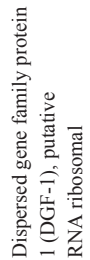

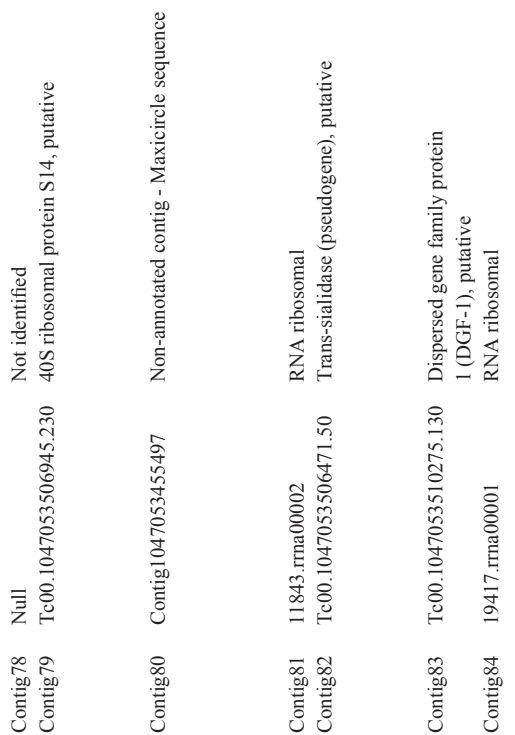


Transcriptome of Trypanosoma cruzi mammalian stages

1607

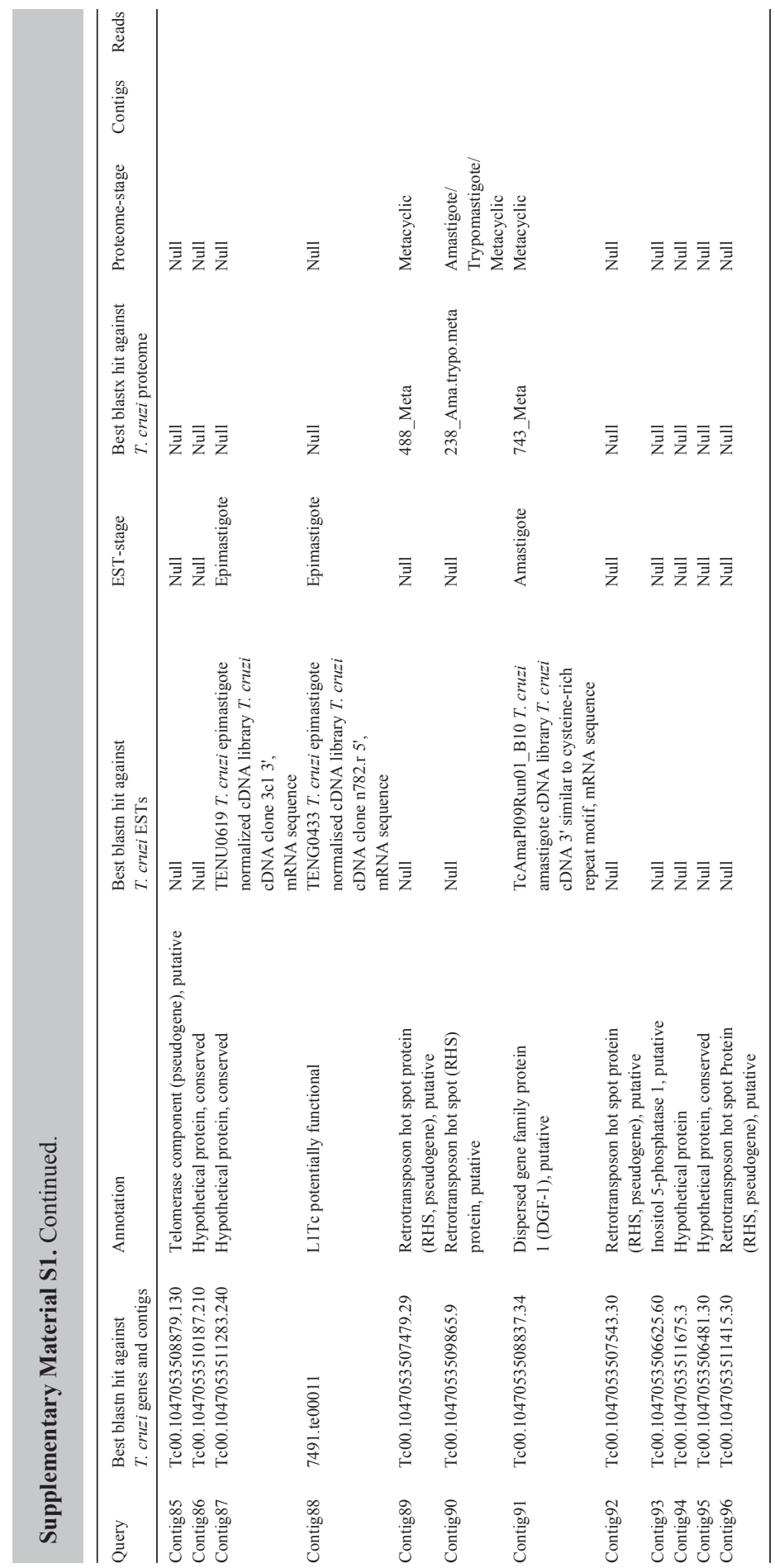

Genetics and Molecular Research 10 (3): 1589-1630 (2011) 
C. Martins et al.

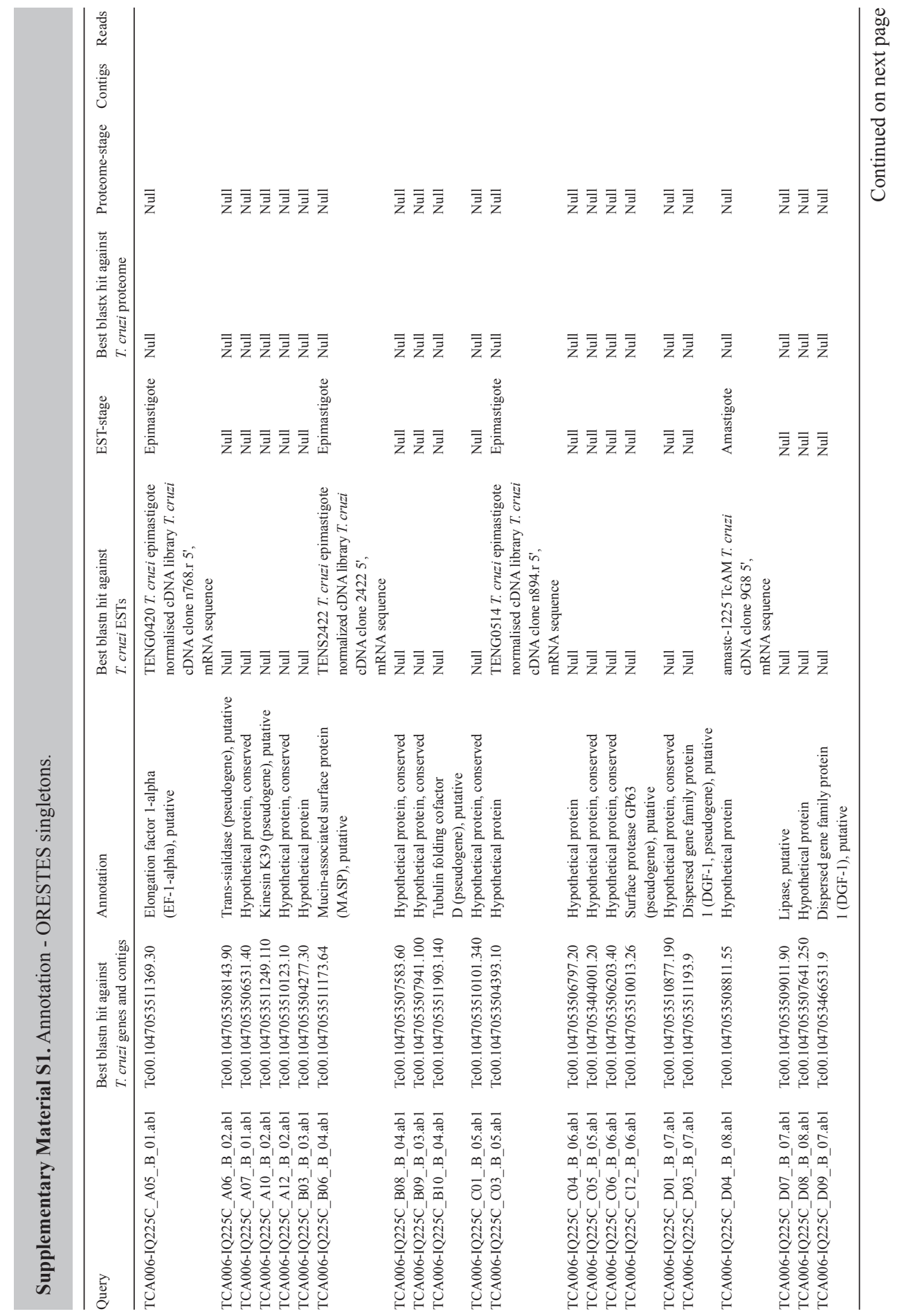


Transcriptome of Trypanosoma cruzi mammalian stages

1609

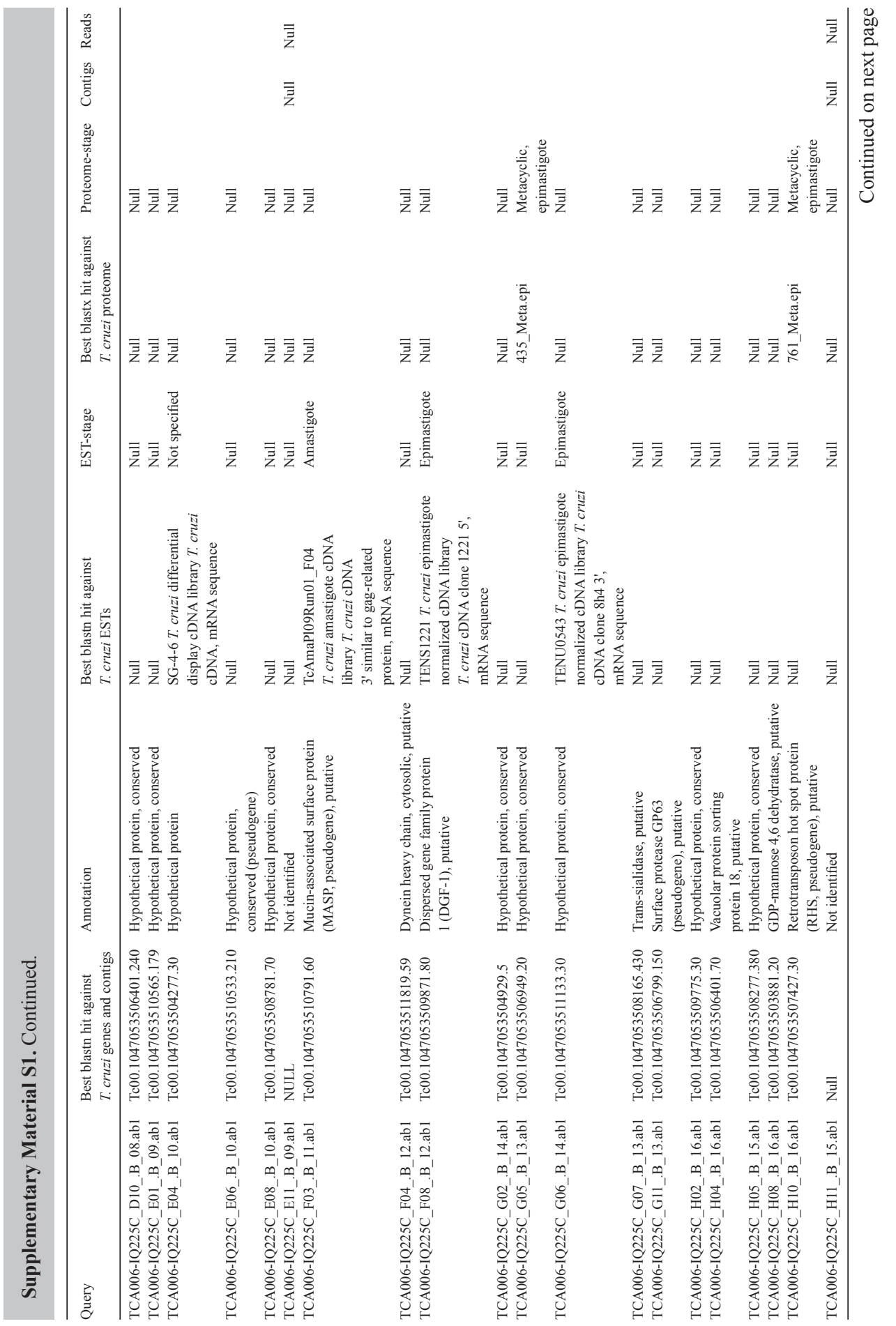

Genetics and Molecular Research 10 (3): 1589-1630 (2011) 
C. Martins et al.

1610

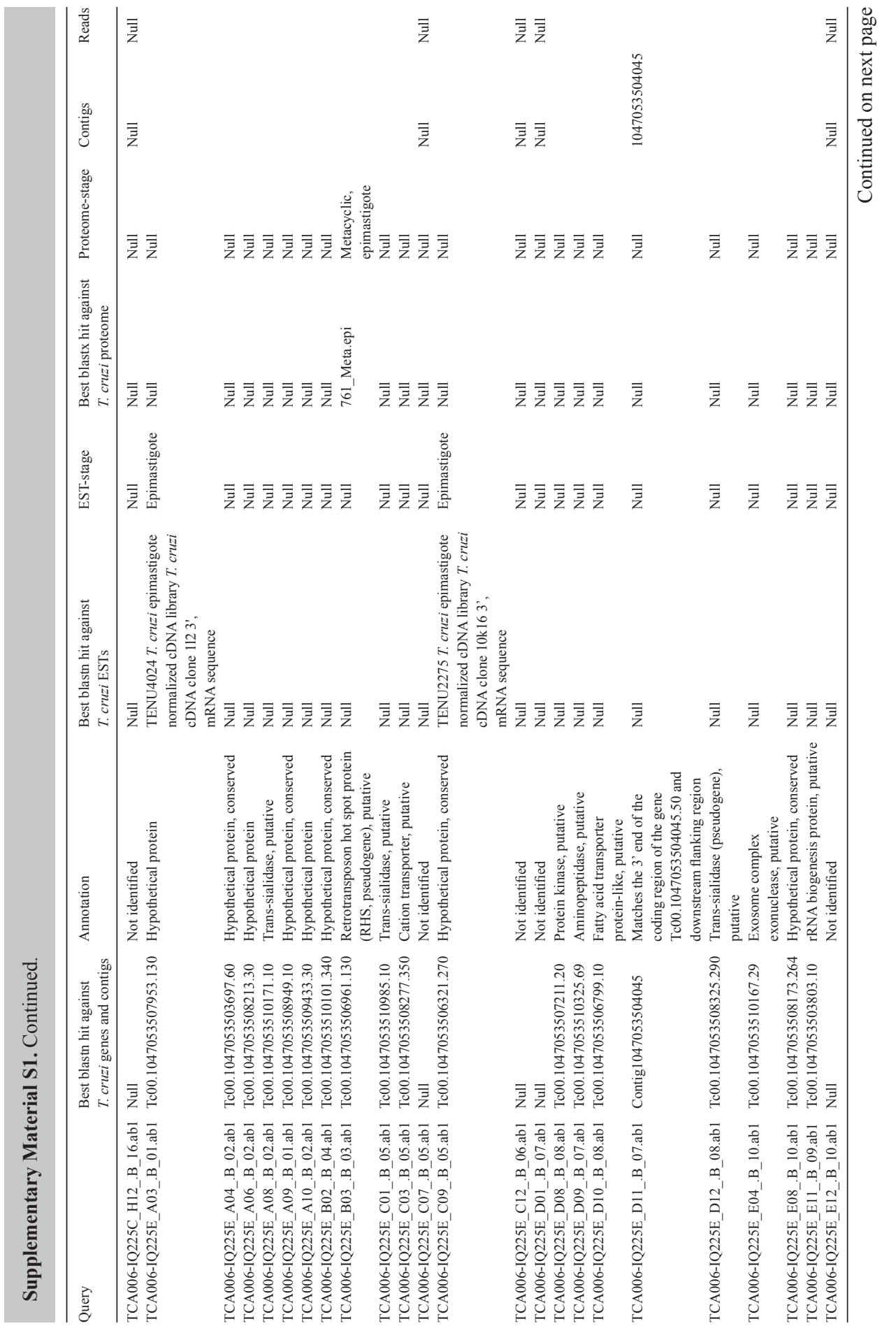


Transcriptome of Trypanosoma cruzi mammalian stages

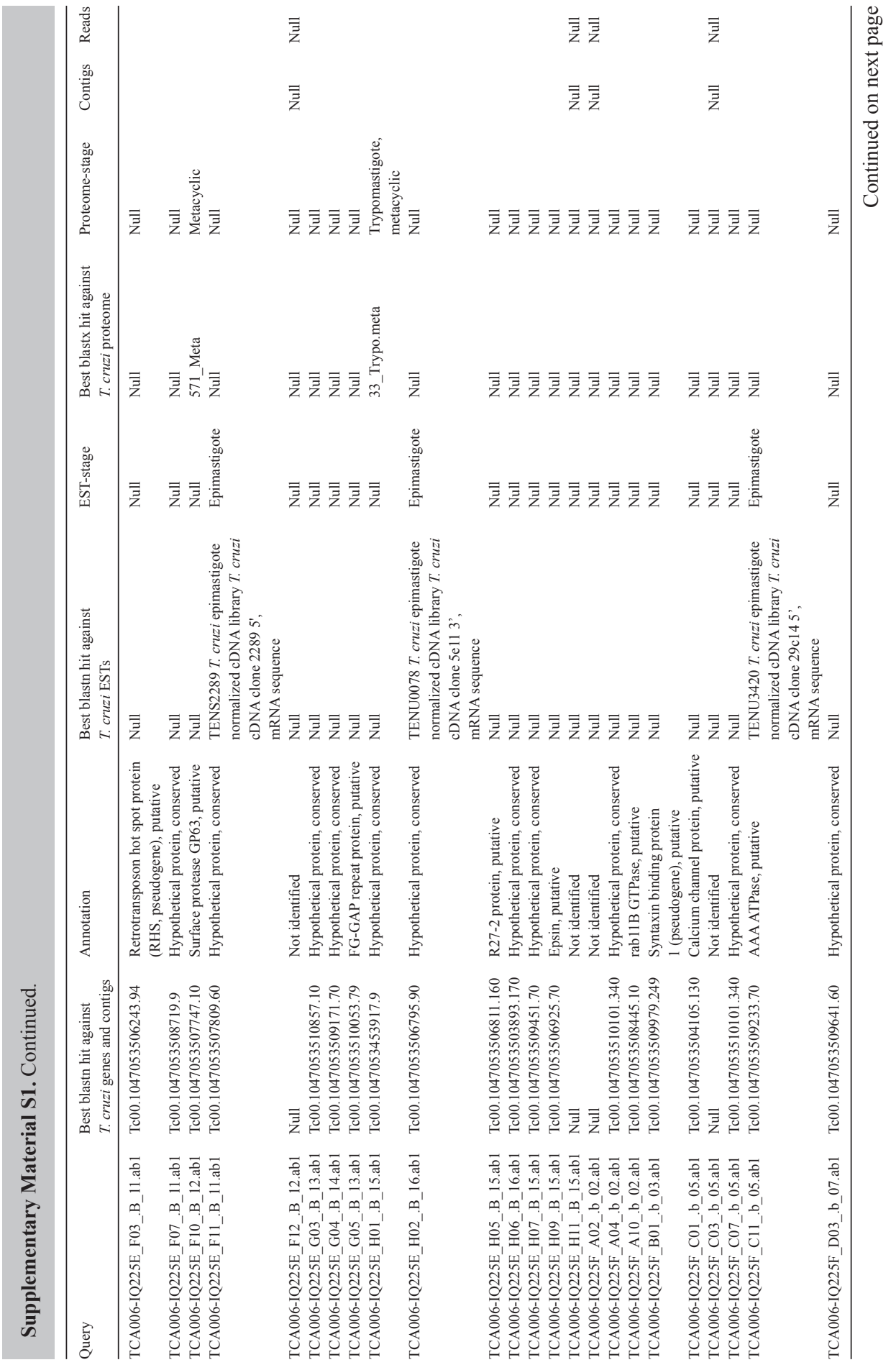


C. Martins et al.

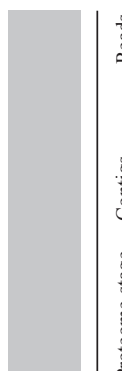

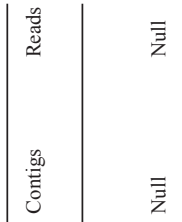

:

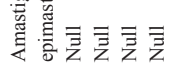

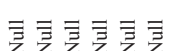

$\overline{\bar{z}}$

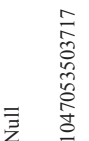

1612

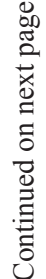

훙

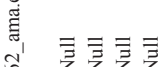

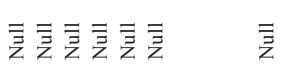

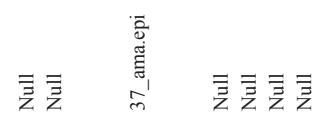

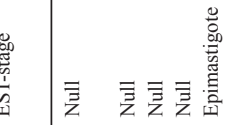

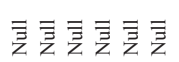

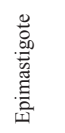

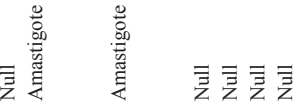

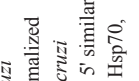

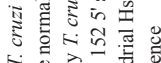

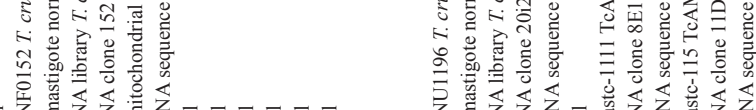

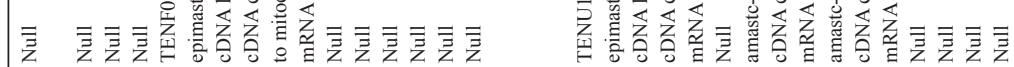
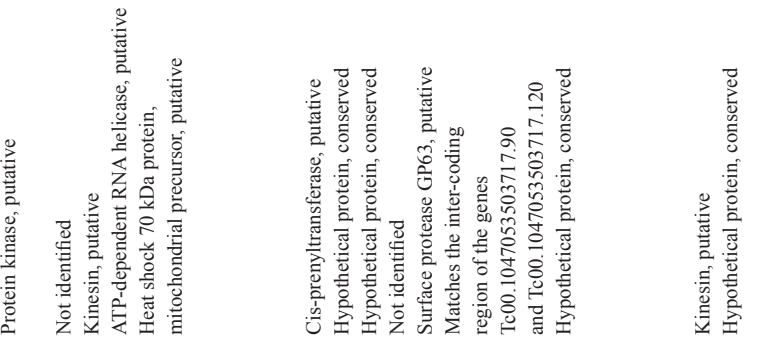

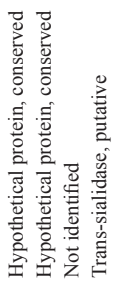

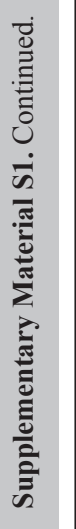

ㅇ. 으의

年

च

守吉

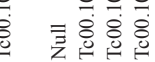

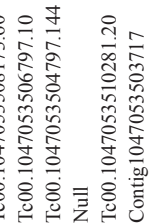

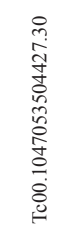

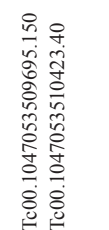

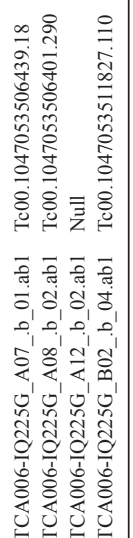

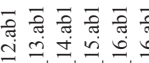

إبـ

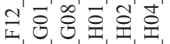

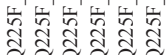

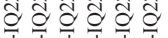

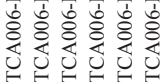

Genetics and Molecular Research 10 (3): 1589-1630 (2011)

CFUNPEC-RP www.funpecrp.com.br 
Transcriptome of Trypanosoma cruzi mammalian stages

1613

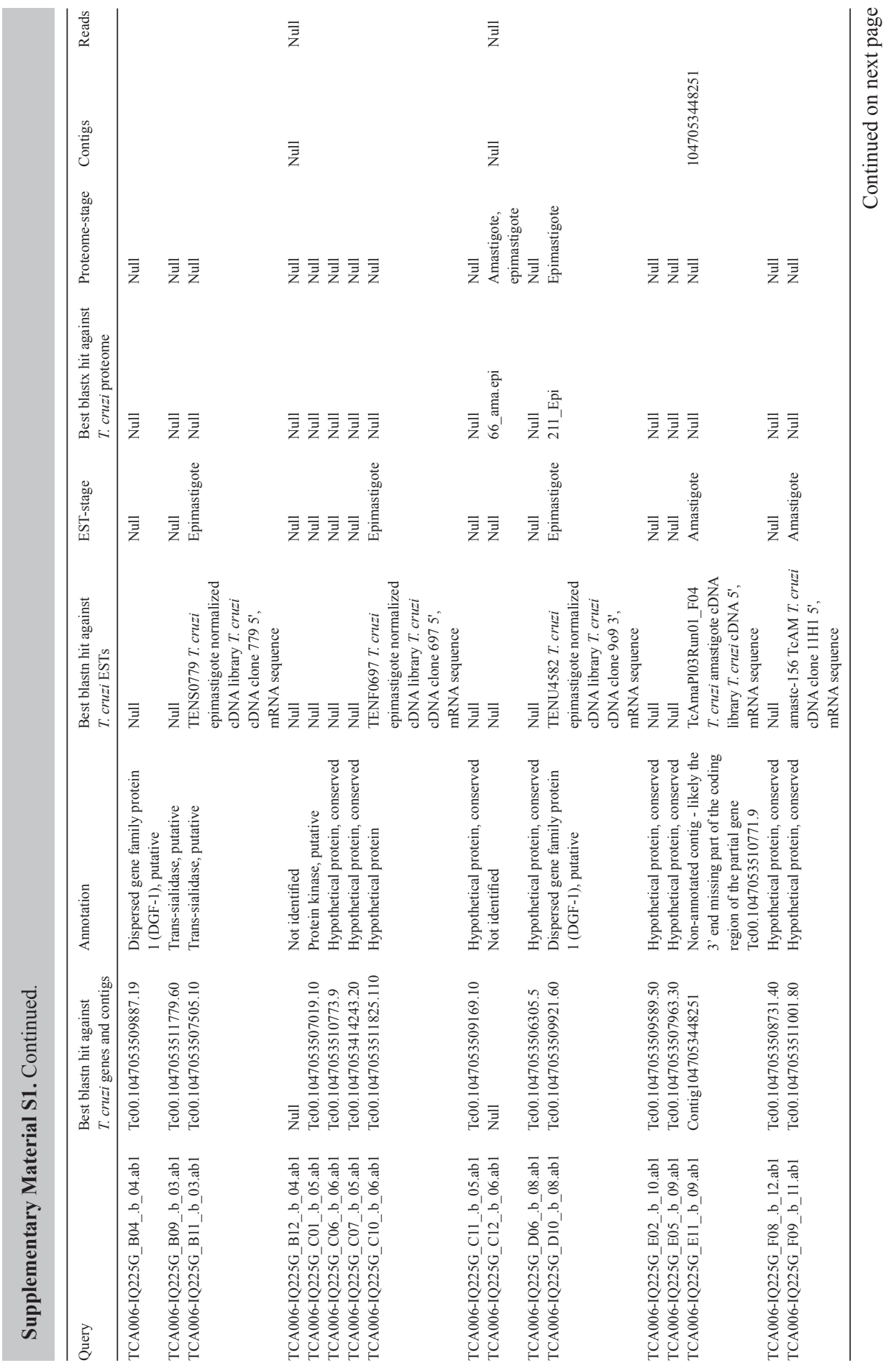

Genetics and Molecular Research 10 (3): 1589-1630 (2011) 
C. Martins et al.

1614

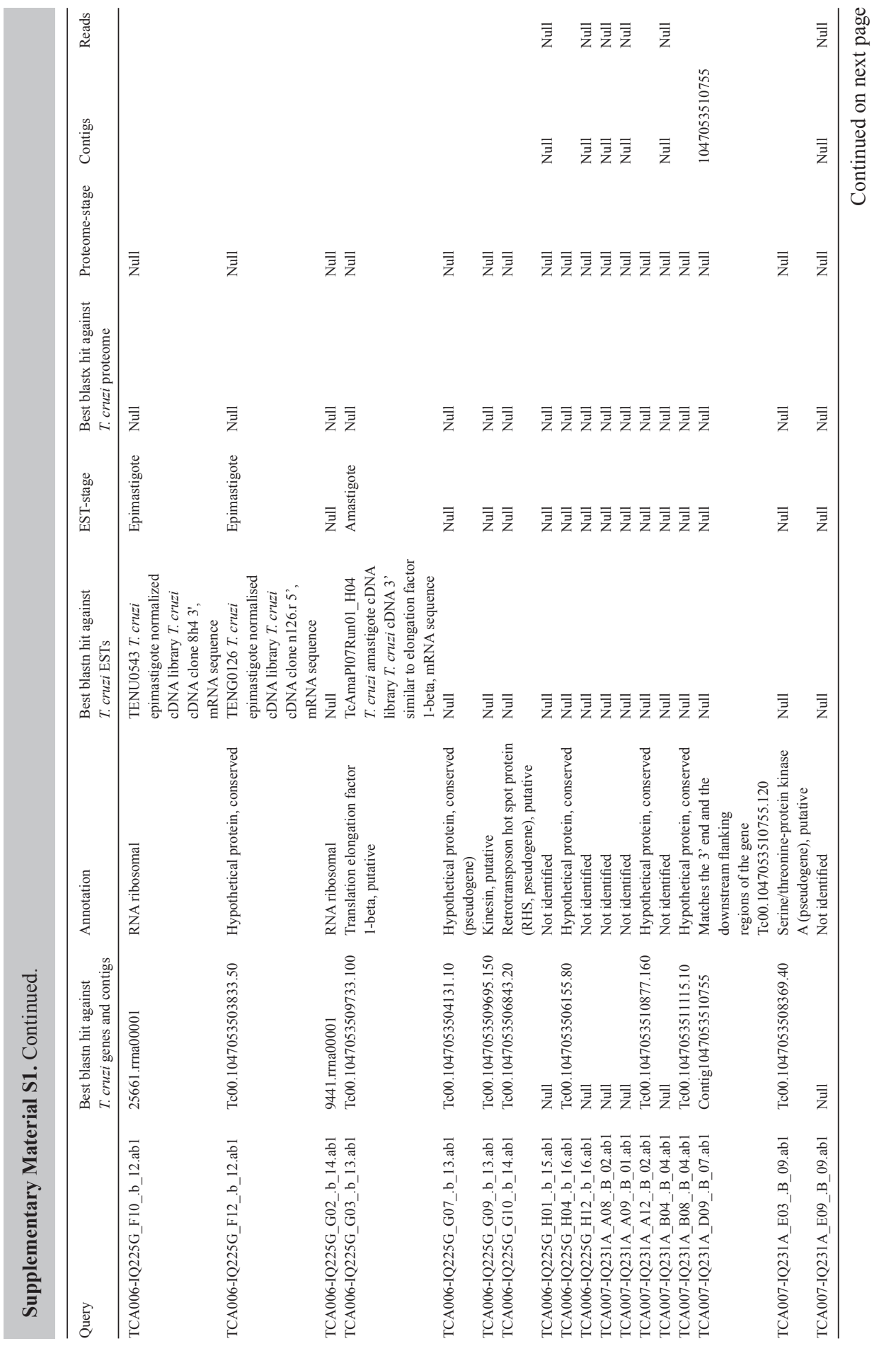


Transcriptome of Trypanosoma cruzi mammalian stages

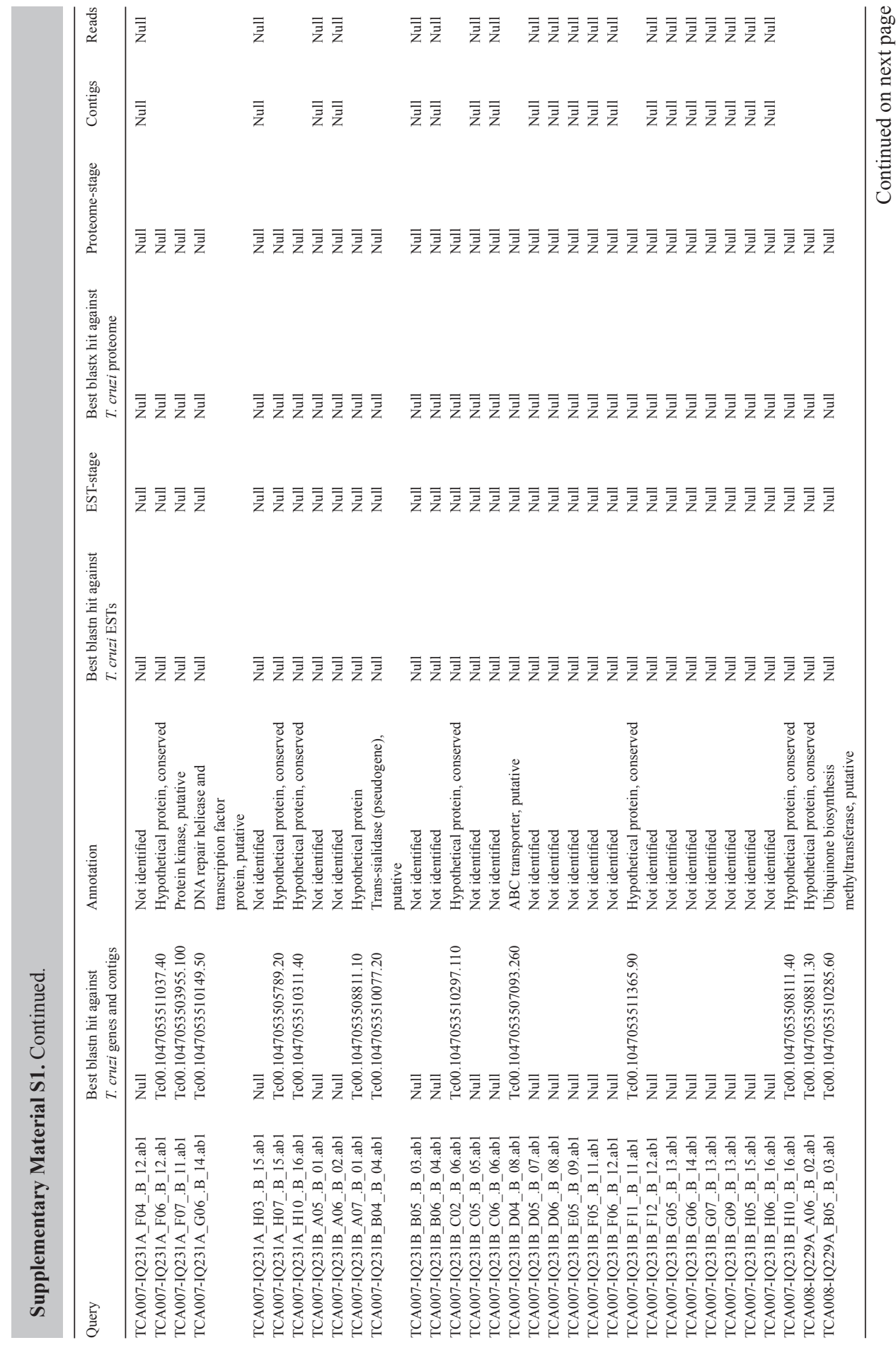


C. Martins et al.

1616

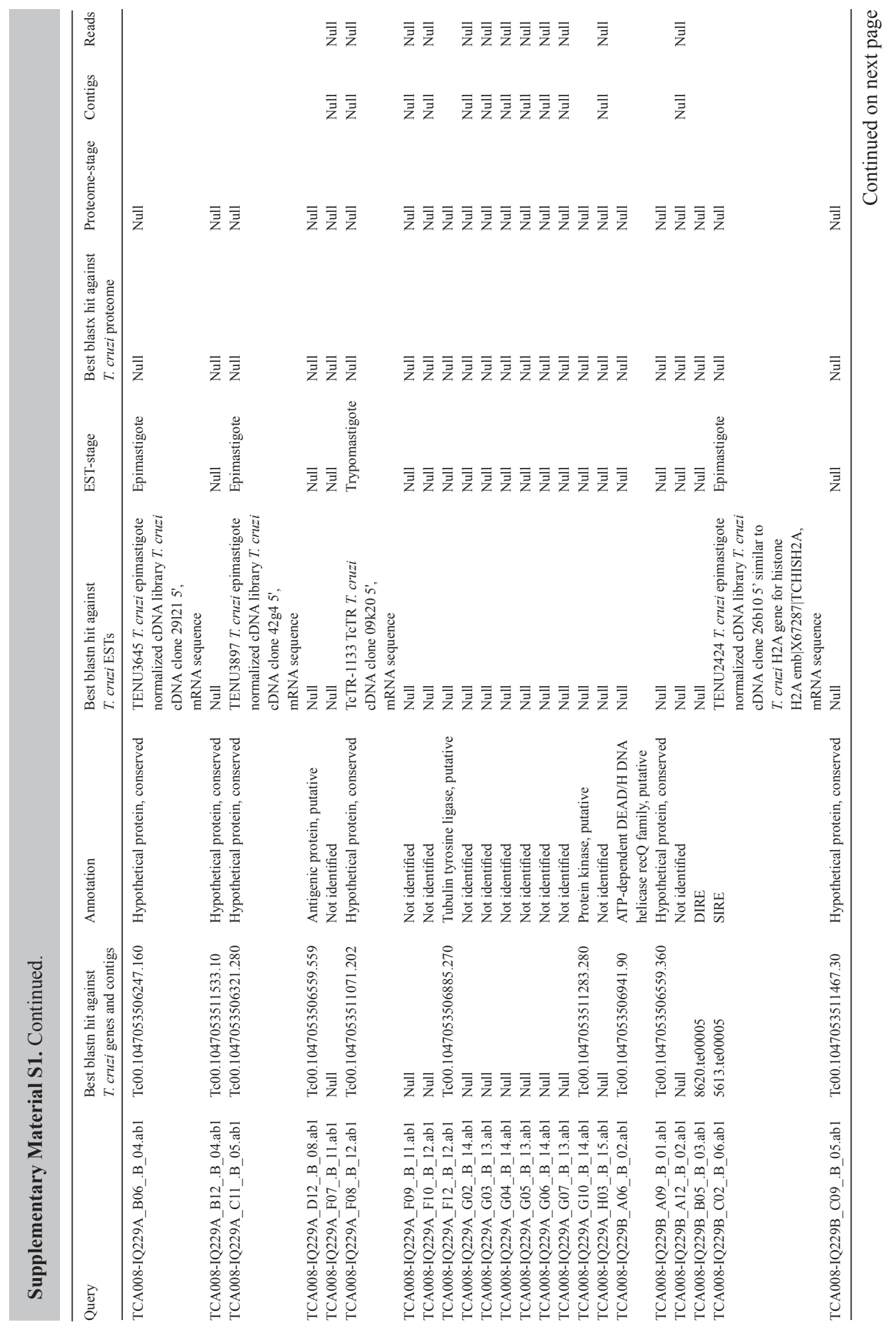




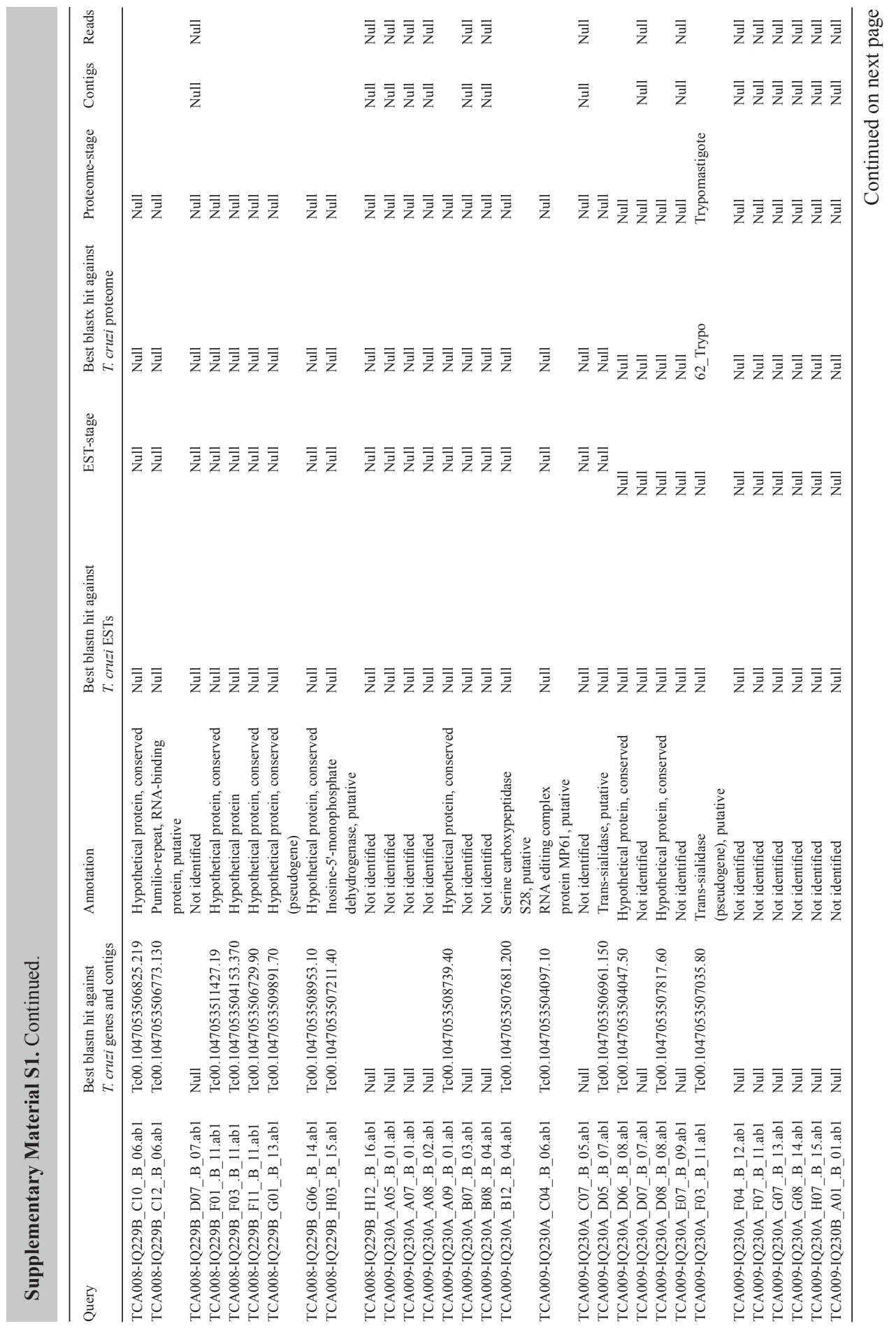


C. Martins et al.

1618

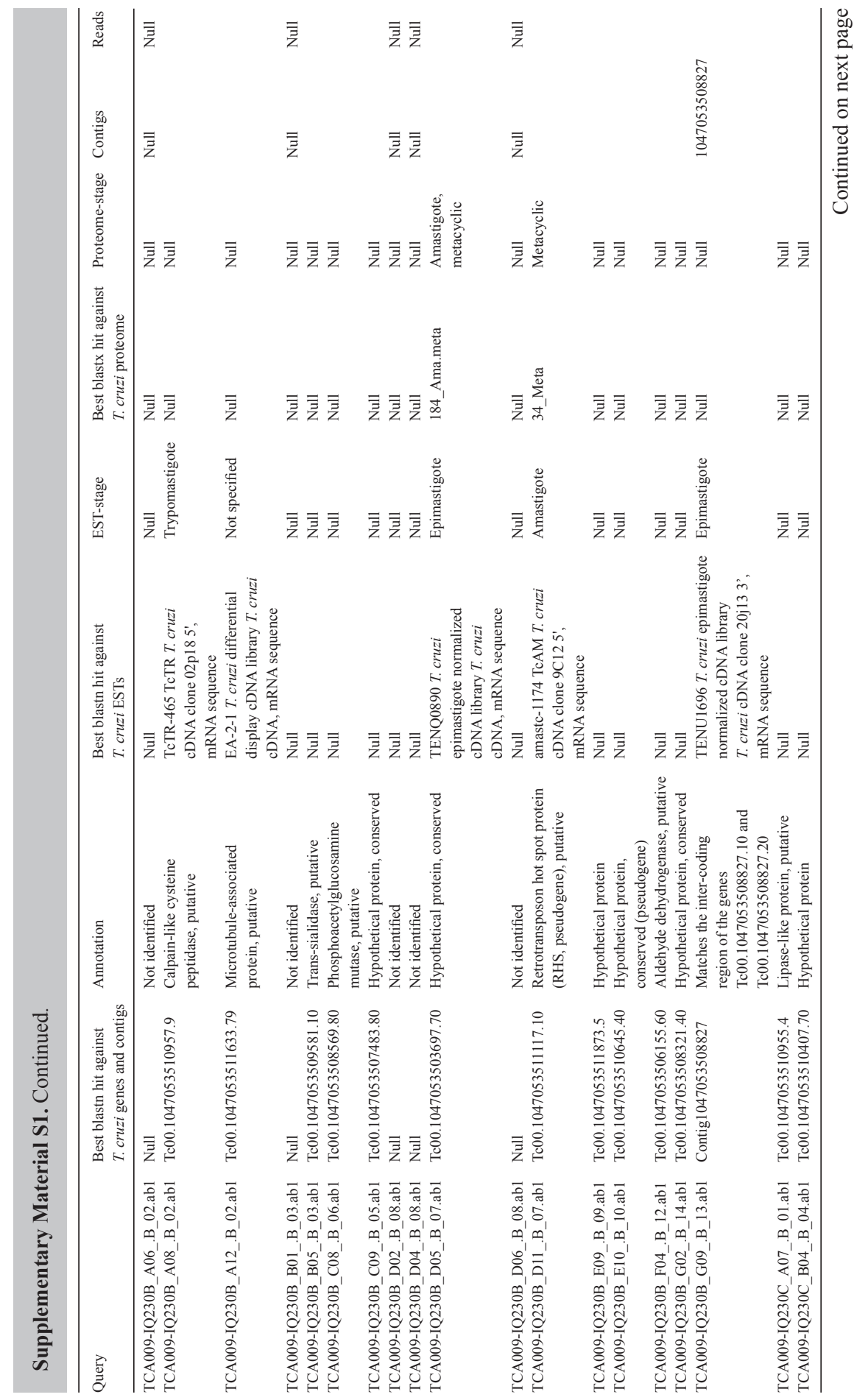

Genetics and Molecular Research 10 (3): 1589-1630 (2011)

CFUNPEC-RP www.funpecrp.com.br 
Transcriptome of Trypanosoma cruzi mammalian stages

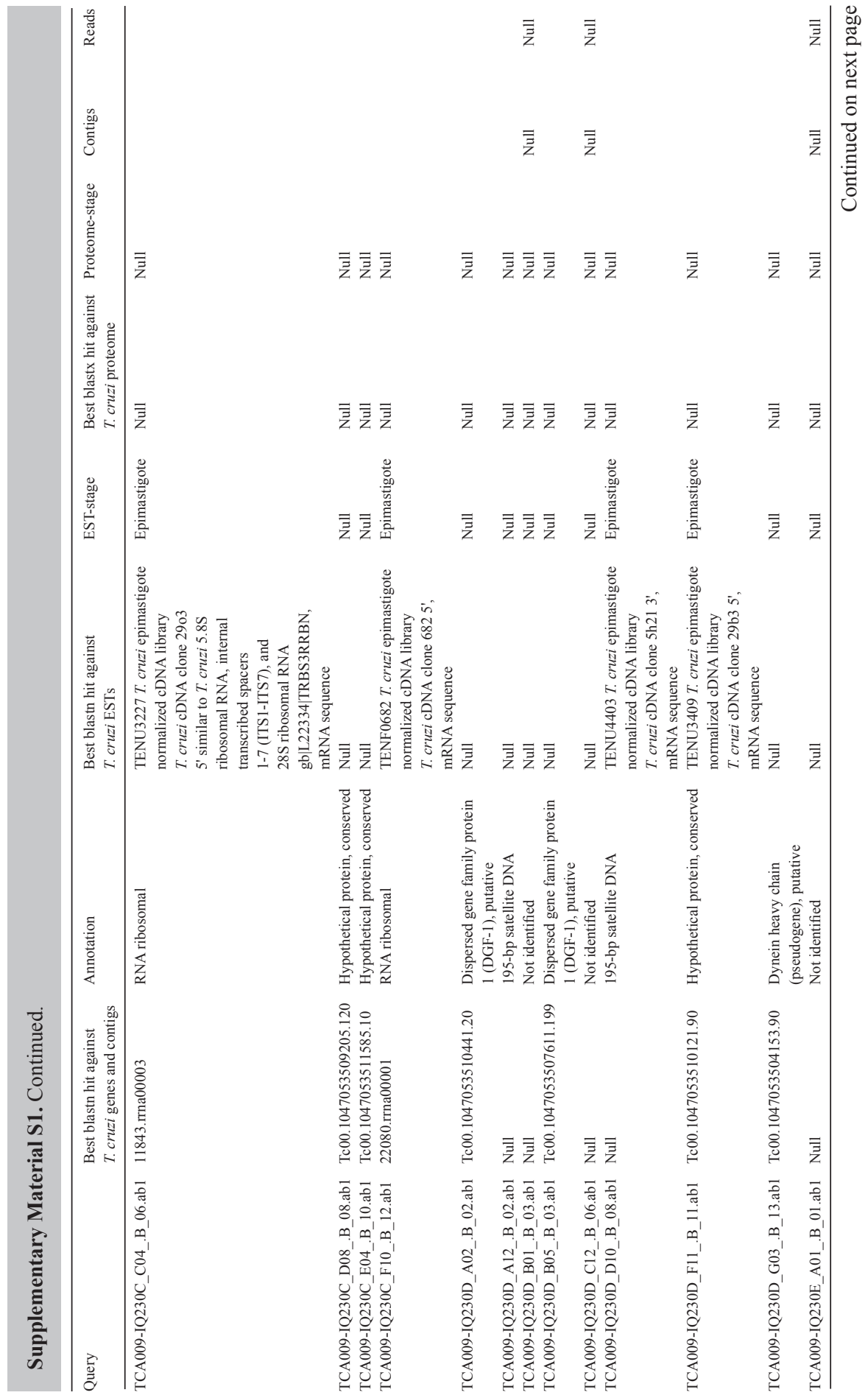


C. Martins et al.

1620

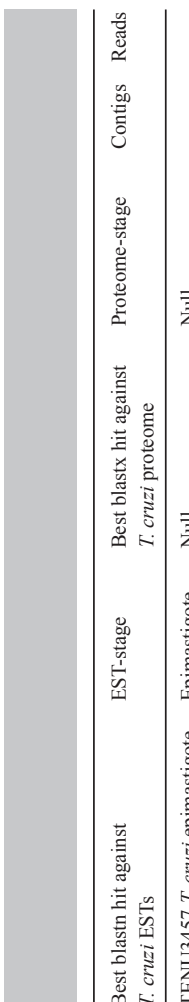

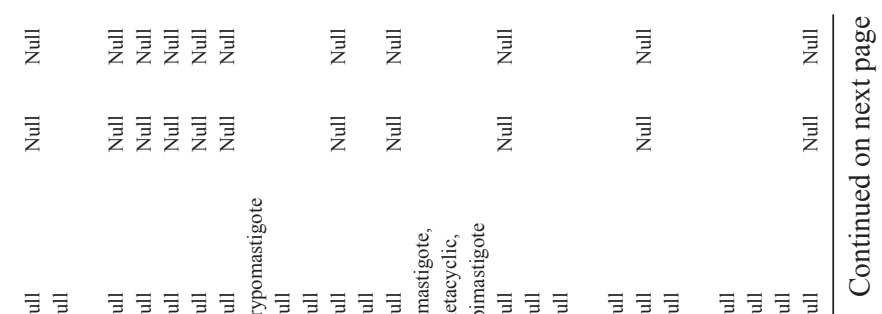

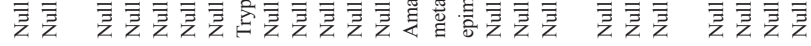

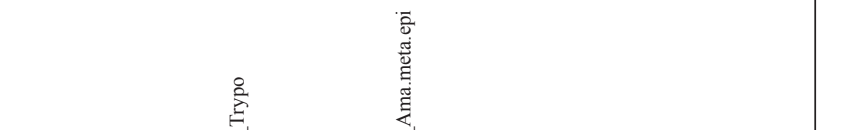

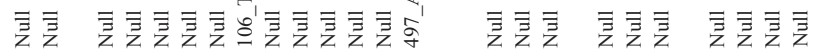

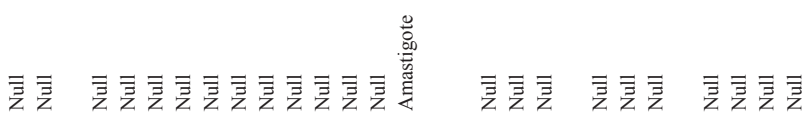

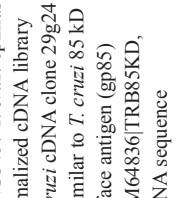

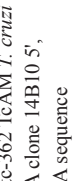

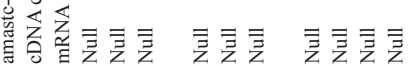

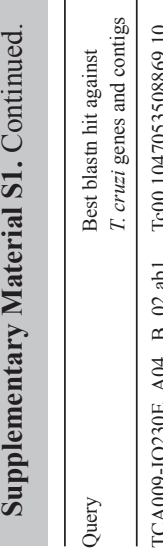

总

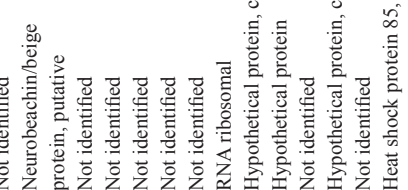

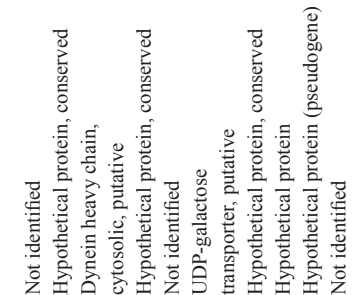

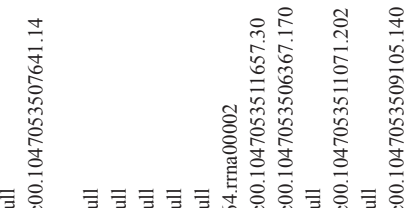

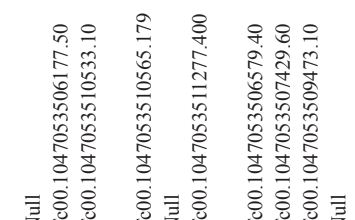

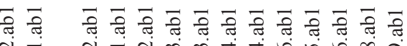

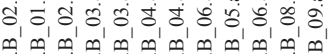

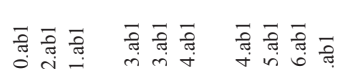

$m m m^{\prime} m m^{\prime} m m^{\prime} m m m$

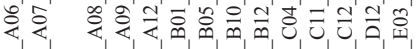

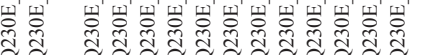

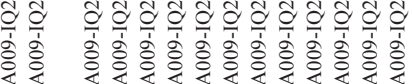

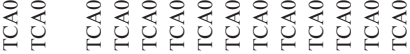

Genetics and Molecular Research 10 (3): 1589-1630 (2011)

CFUNPEC-RP www.funpecrp.com.br 
Transcriptome of Trypanosoma cruzi mammalian stages

1621

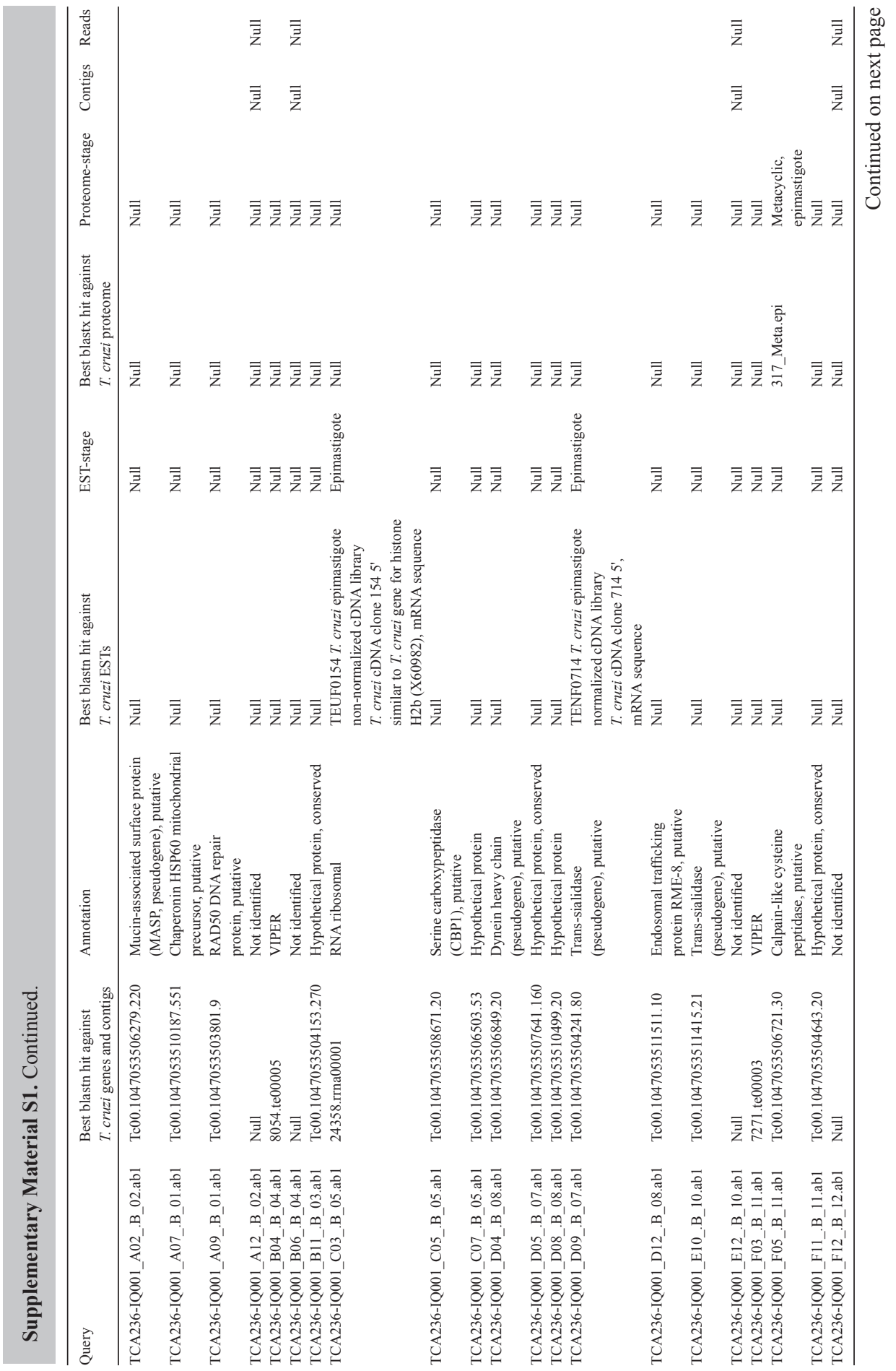


C. Martins et al.

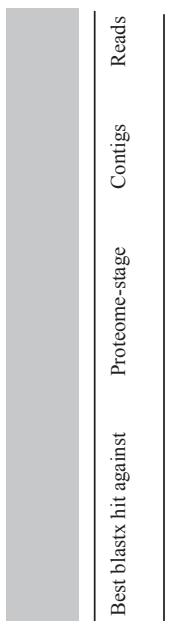

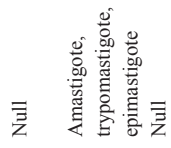
(1)

垔

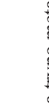

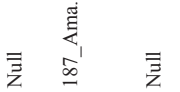

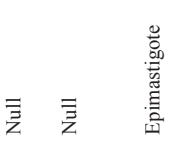

言袬

言 言

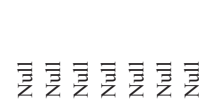

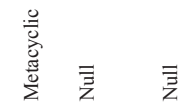

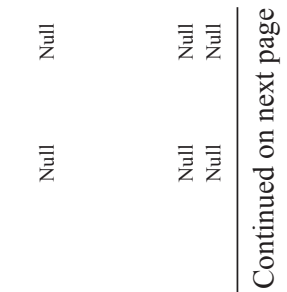

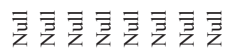

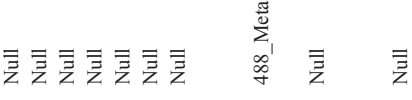

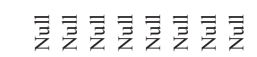

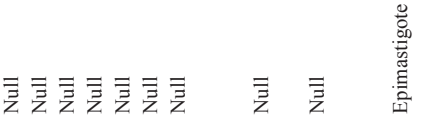

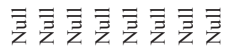
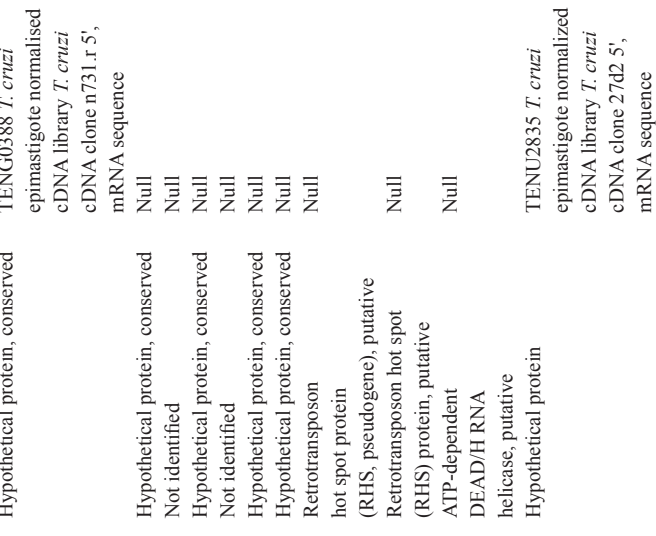

\section{8

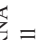

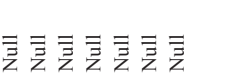


Transcriptome of Trypanosoma cruzi mammalian stages

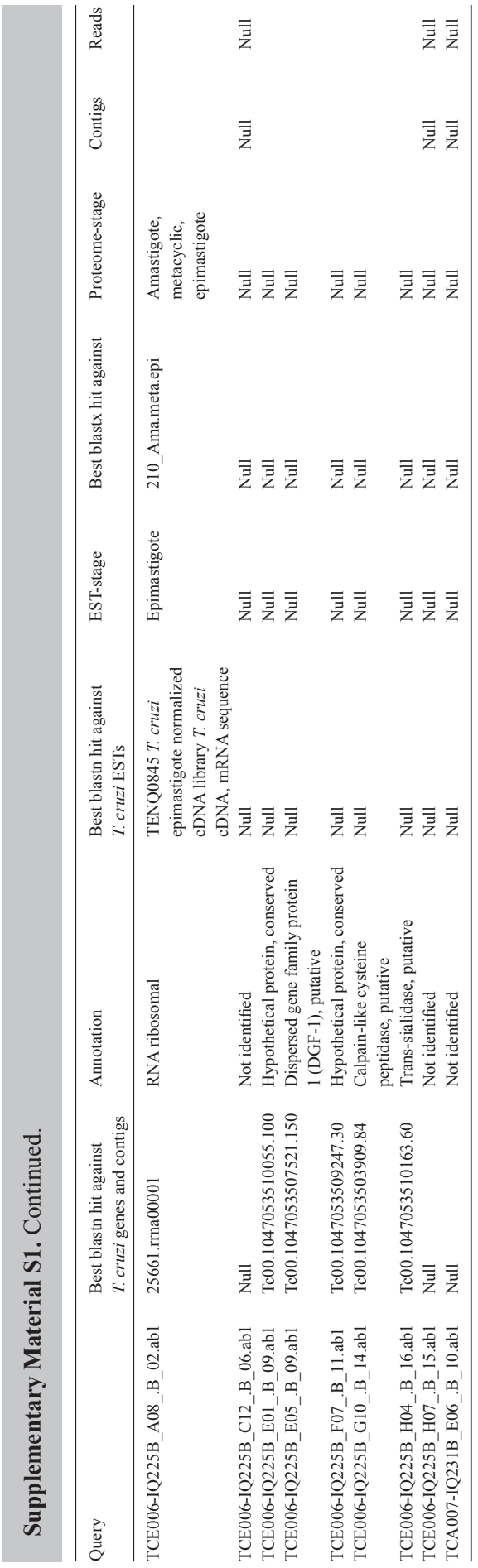


C. Martins et al.

1624

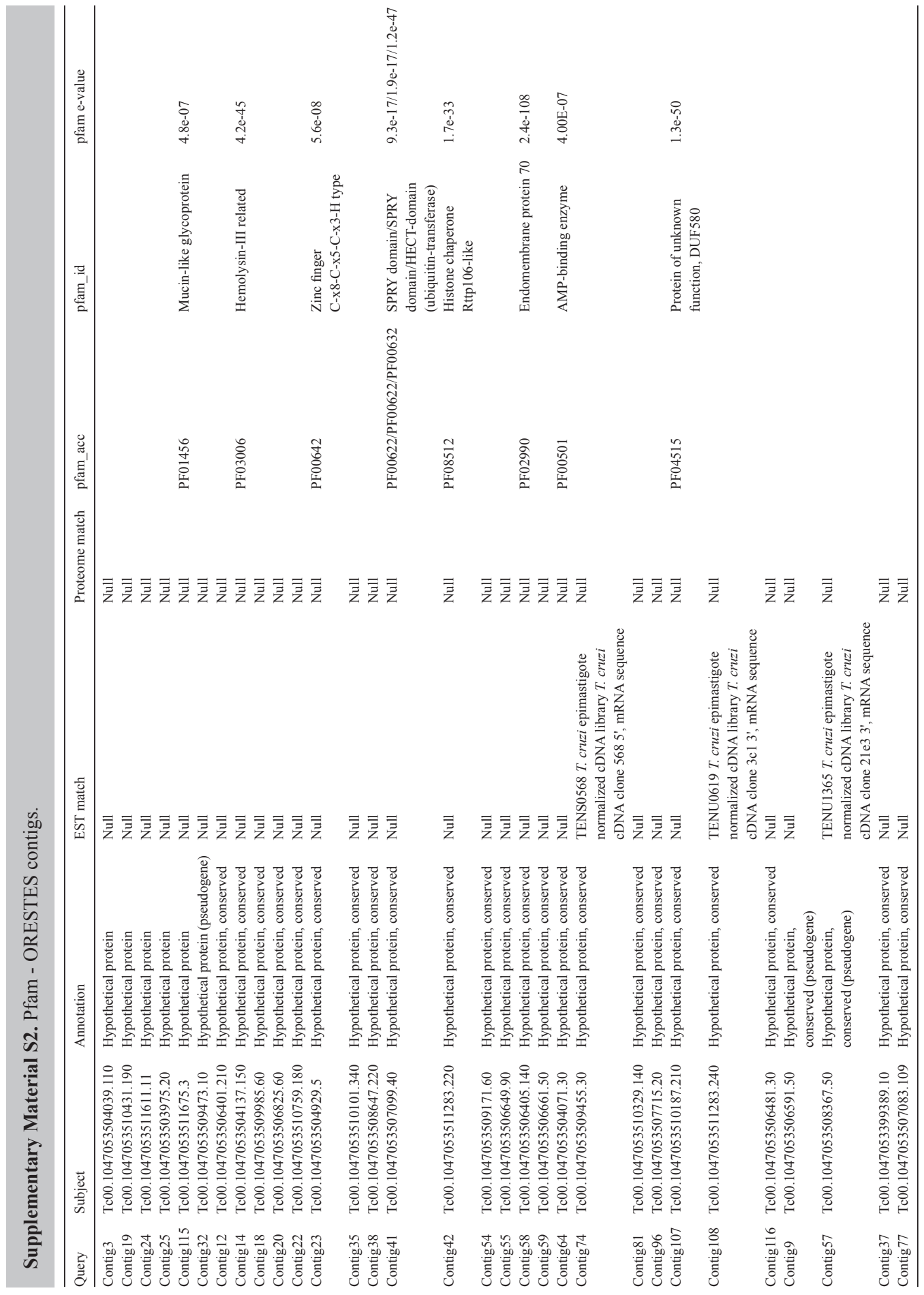

Genetics and Molecular Research 10 (3): 1589-1630 (2011) 
Transcriptome of Trypanosoma cruzi mammalian stages
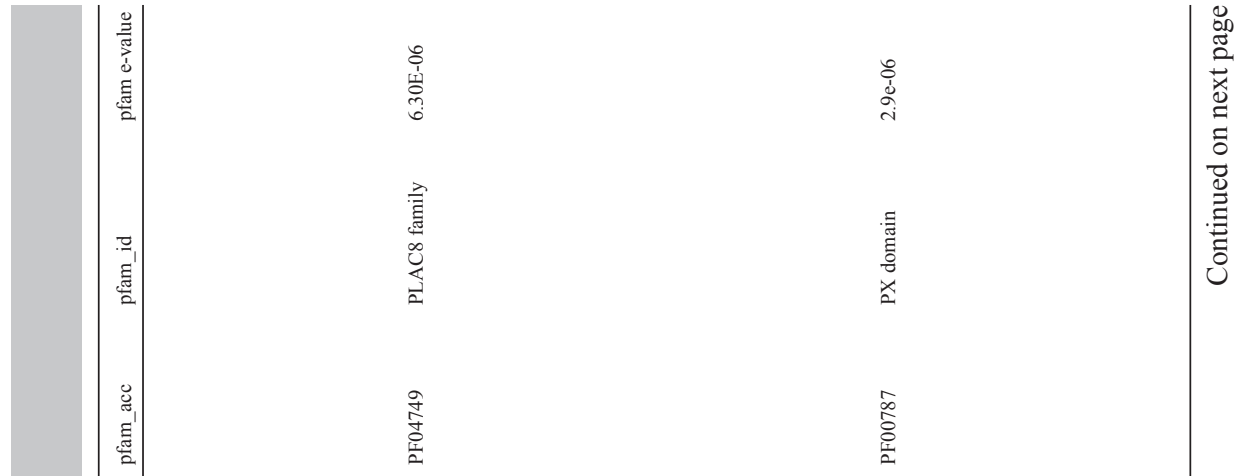

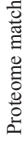

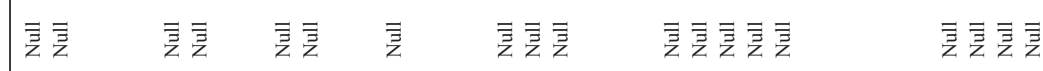

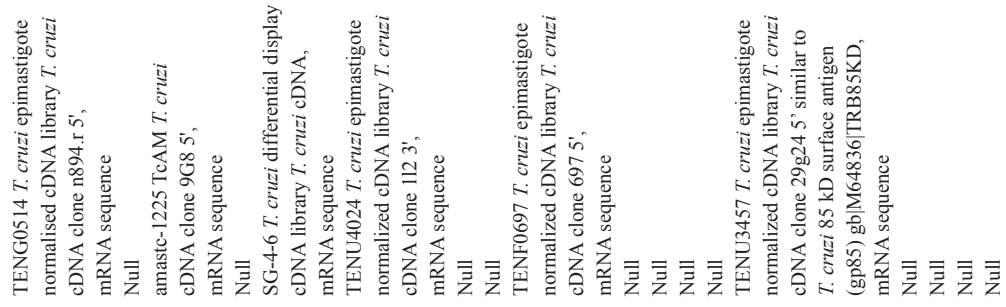
(1) 
C. Martins et al.

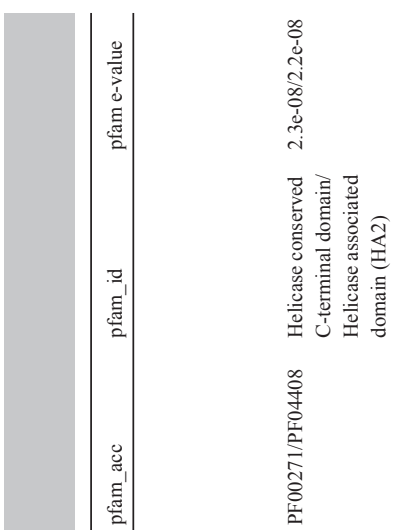

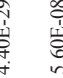

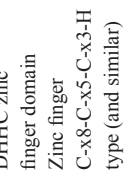

空

这

$\overline{\overline{\bar{z}}} \overline{\overline{\bar{z}}}$

定

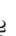

然

in

这罂

范

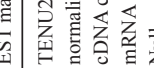

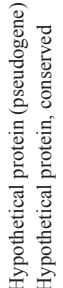

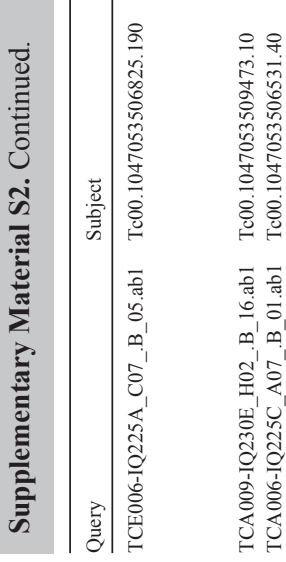

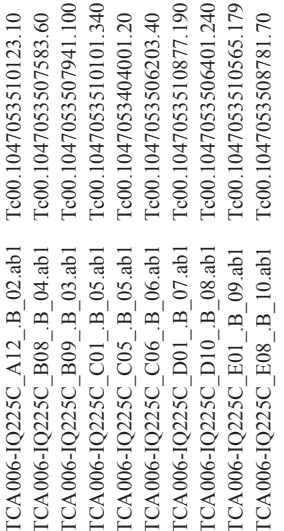

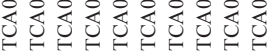

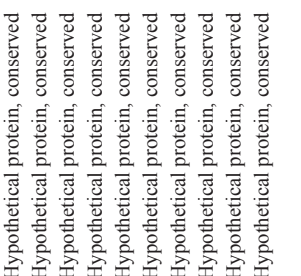

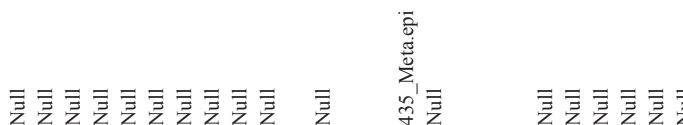
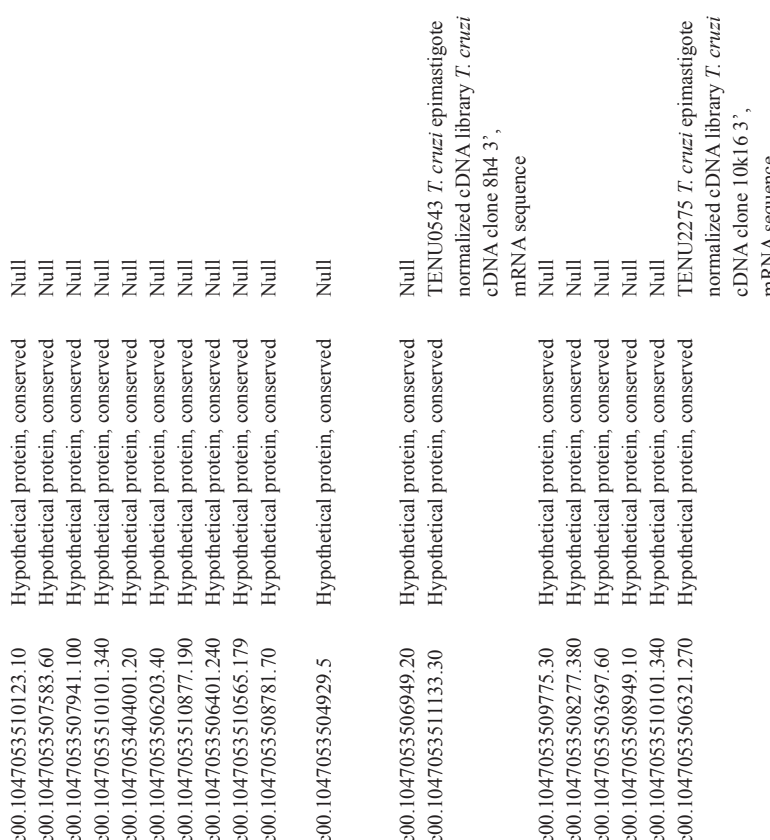

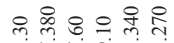

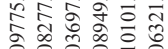

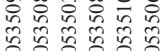

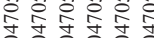

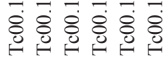

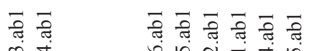

m, m

$n^{\prime} n^{\prime}$

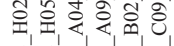

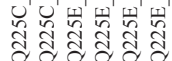

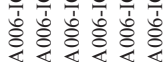

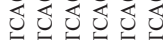


Transcriptome of Trypanosoma cruzi mammalian stages

1627

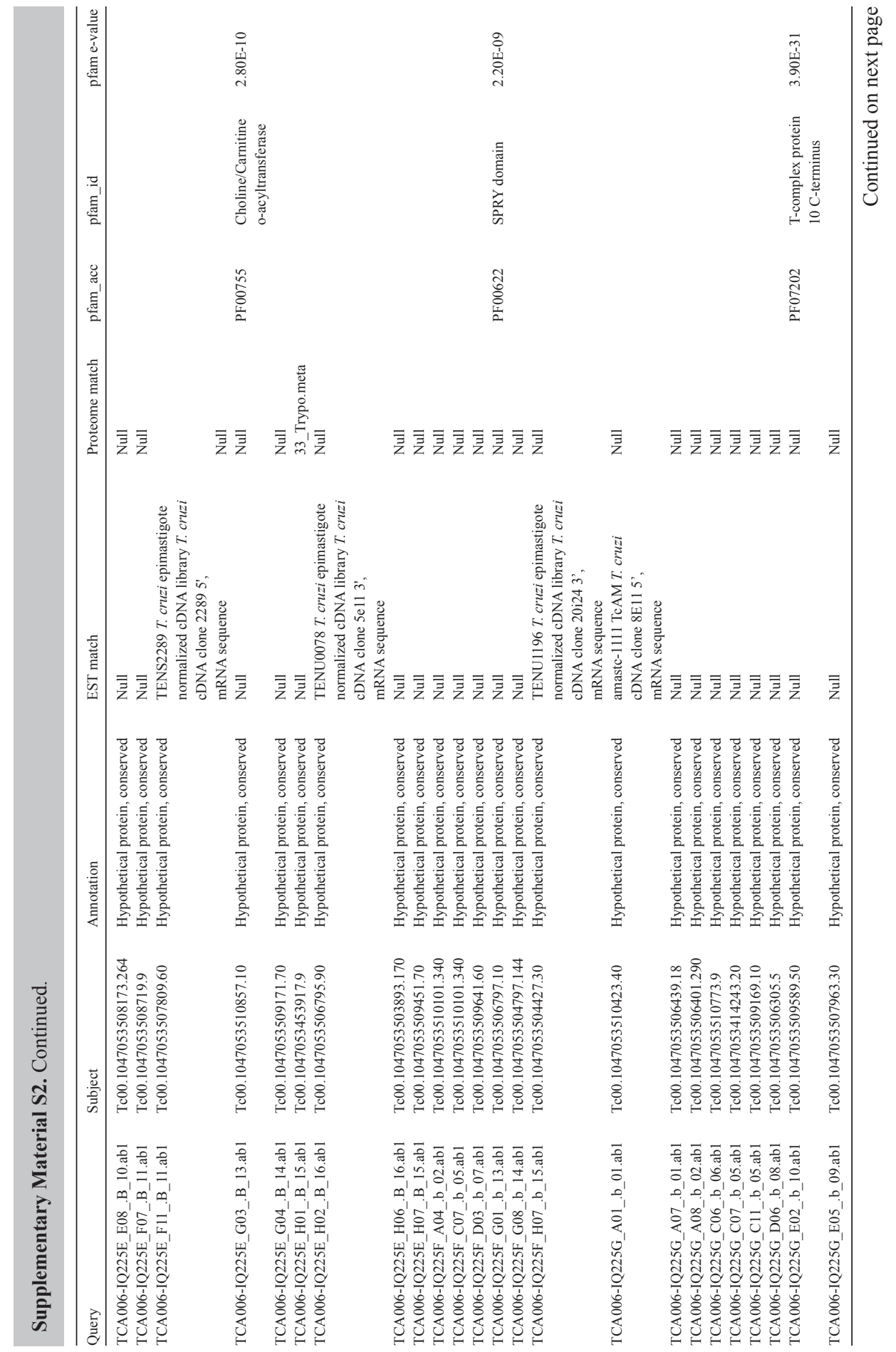

Genetics and Molecular Research 10 (3): 1589-1630 (2011)

CFUNPEC-RP www.funpecrp.com.br 
C. Martins et al.
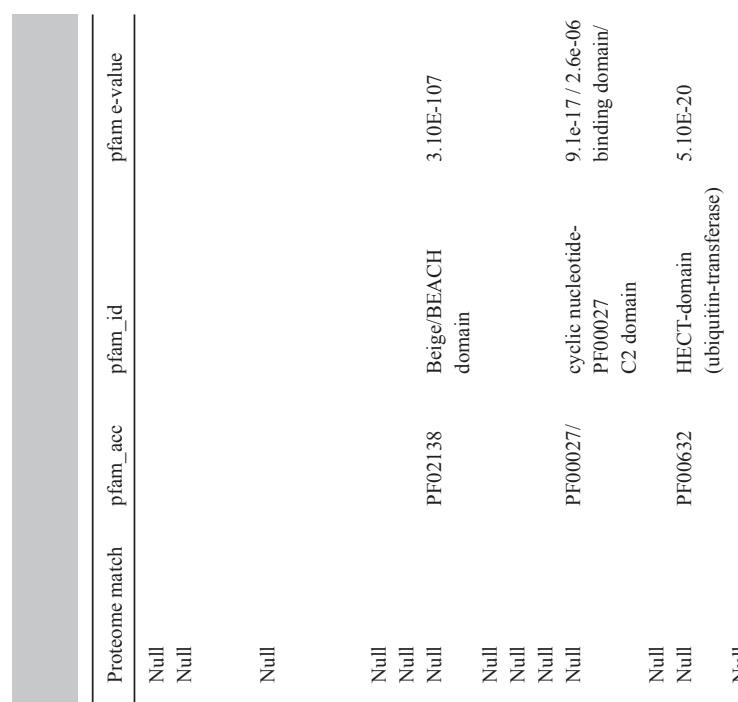

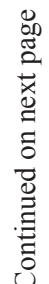

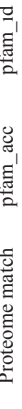

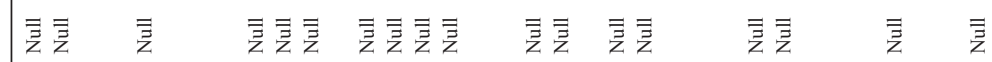

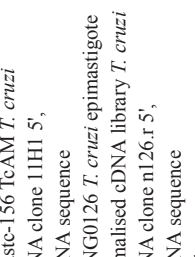

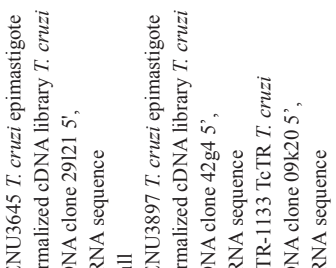

言言
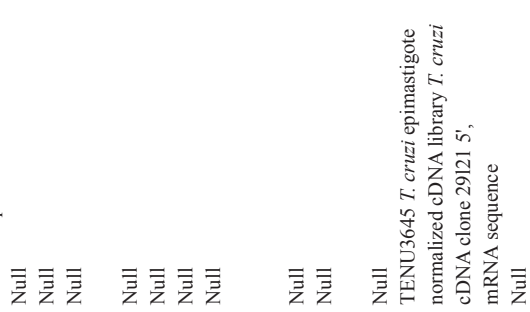

空

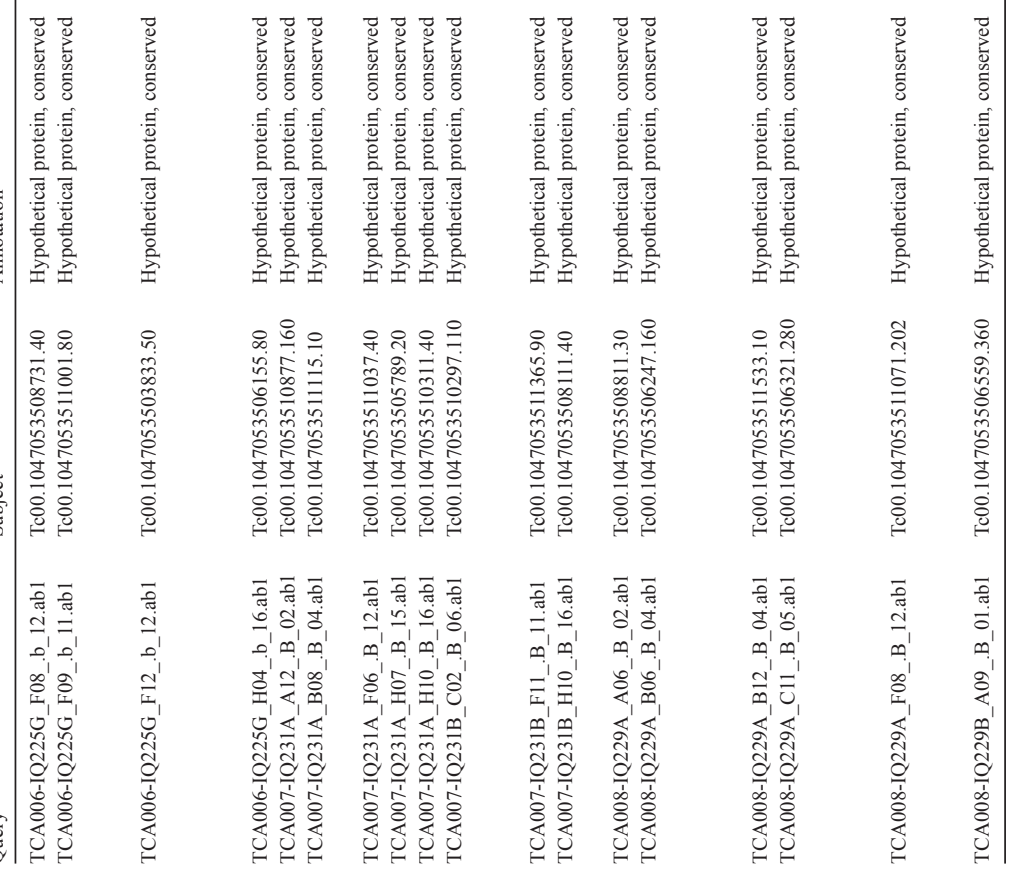


Transcriptome of Trypanosoma cruzi mammalian stages

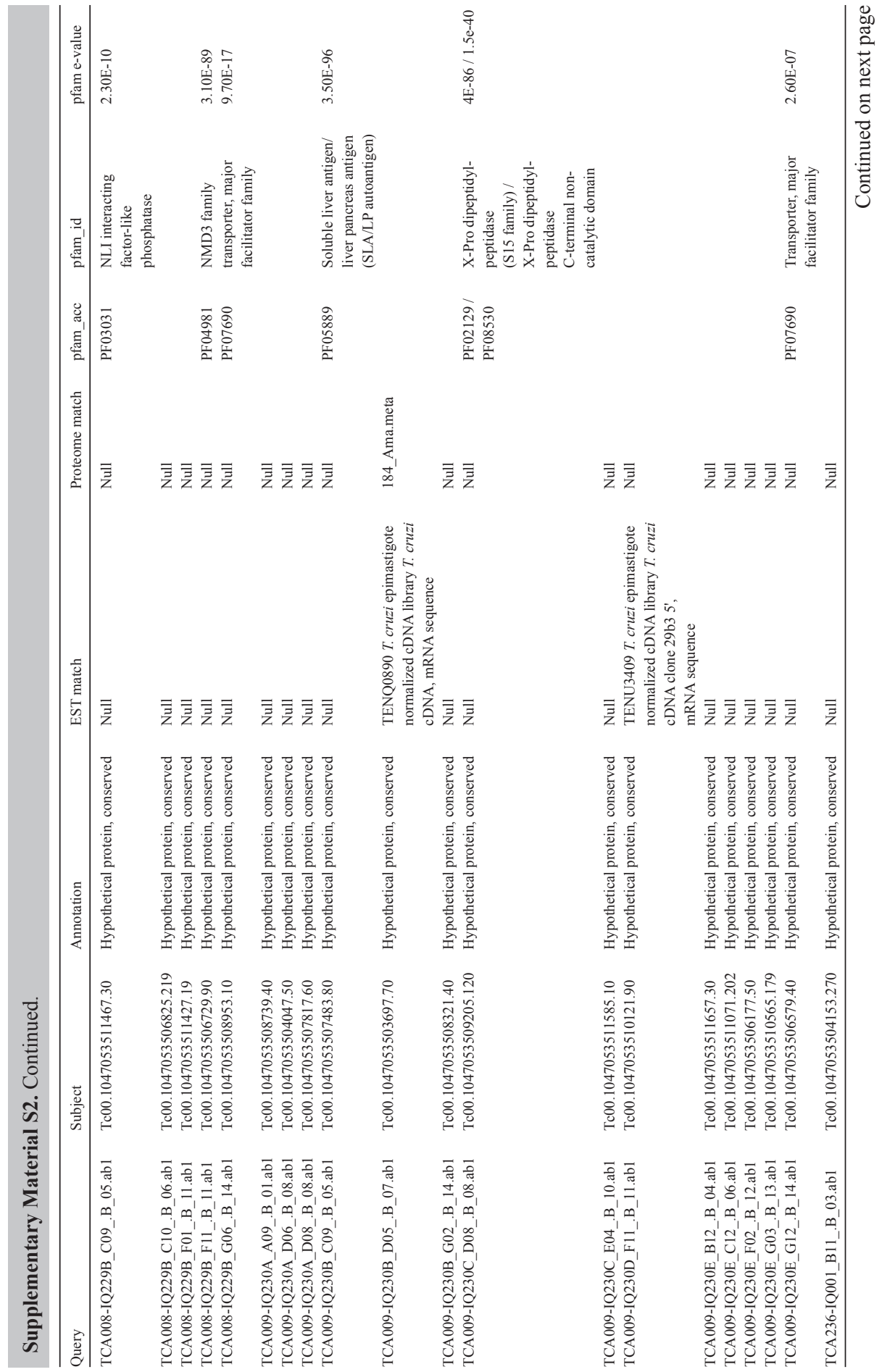


C. Martins et al.

1630

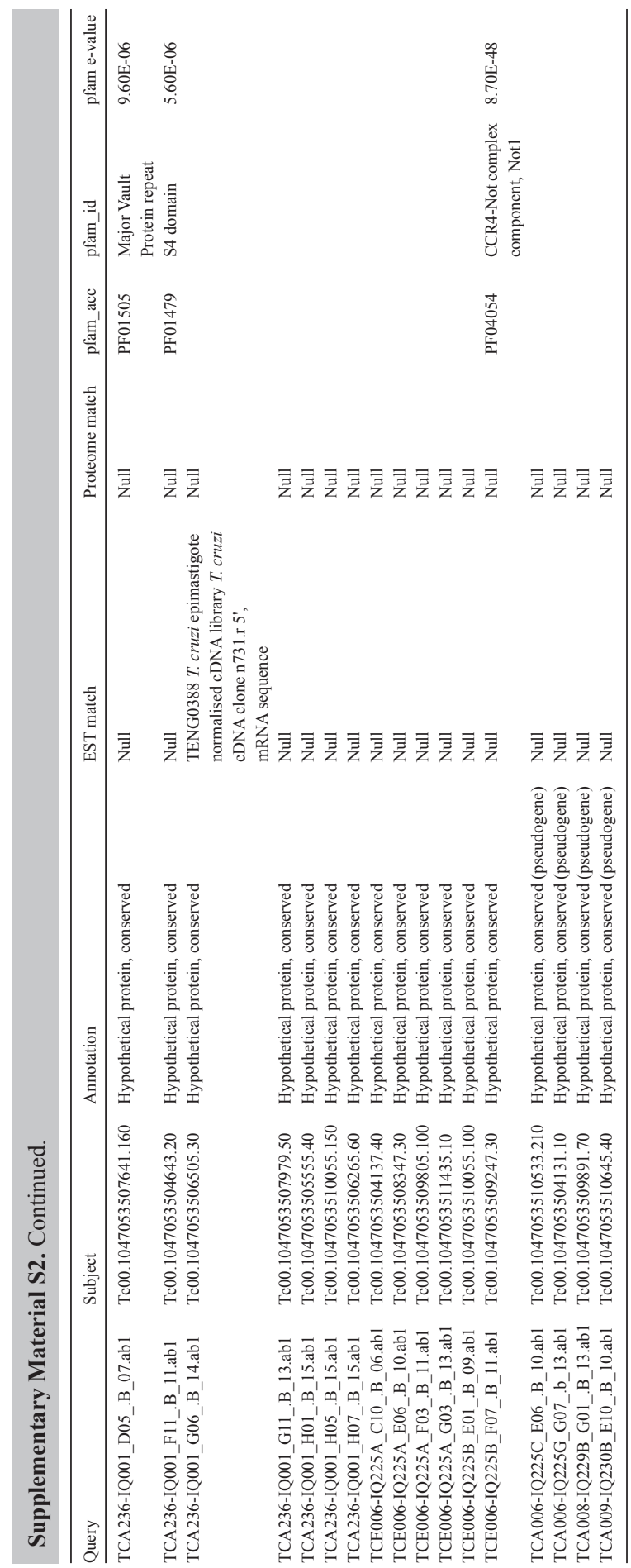

Genetics and Molecular Research 10 (3): 1589-1630 (2011) 